\title{
Growth as a Solid Tumor or Reduced Glucose Concentrations in Culture Reversibly Induce CD44-mediated Hyaluronan Recognition by Chinese Hamster Ovary Cells
}

\author{
Zhong Zheng, ${ }^{*}$ Richard D. Cummings, ${ }^{\ddagger}$ Philip E. Pummill, ${ }^{\ddagger}$ and Paul W. Kincade* \\ *Oklahoma Medical Research Foundation, Oklahoma City, Oklahoma 73104; and ${ }^{\ddagger}$ Department of Biochemistry and Molecular Biology, \\ University of Oklahoma Health Sciences Center, Oklahoma City, Oklahoma 73104
}

\begin{abstract}
The density, molecular isoform, and posttranslational modifications of CD44 can markedly influence growth and metastatic behavior of tumors. Many CD44 functions, including some involving tumors, have been attributed to its ability to recognize hyaluronan (HA). However, only certain CD44bearing cells bind soluble or immobilized HA. We now show that CD44 made by wild-type Chinese hamster ovary (CHO-K1) cells and a ligand-binding subclone differ with respect to $\mathrm{N}$-linked glycosylation. While both bear CD44 with highly branched, complex-type glycoforms, CD44 expressed by the wild type was more extensively sialylated. CHO-K1 cells which failed to recognize HA when grown in culture gained this ability when grown as a solid tumor and reverted to a non-HA-binding state when returned to culture. The ability of CHO-K1 cells to recognize $\mathrm{HA}$ was also reversibly induced when glucose concentrations in the medium were reduced. Glucose restriction influenced CD44-mediated HA binding by many but not all, of a series of murine tumors. Glucose concentrations and glycosylation inhibitors only partially influenced CD44 receptor function on resting murine B lymphocytes. These observations suggest that glucose levels or other local environmental conditions may markedly influence glycosylation pathways used by some tumor cells, resulting in dramatic alteration of CD44-mediated functions. (J. Clin. Invest. 1997. 100:1217-1229.) Key words: cell adhesion • glycosylation • extracellular matrix • blood glucose $\bullet$ tumors
\end{abstract}

\section{Introduction}

CD44 is a widely expressed transmembrane glycoprotein with structural homology to neurocan, versican, aggrecan, brevican, cartilage link protein, glial HABP, and Tsg6a (1-7). These molecules are collectively referred to as hyaladherins because of their ability to recognize the matrix polymer hyaluronan (HA), ${ }^{1}$ an interaction that may be critical to a wide variety of functions (8-10). For example, CD44 has been implicated in

Address correspondence to Paul W. Kincade, Ph.D., 825 N.E. 13th Street, Oklahoma City, OK 73104. Phone: 405-271-7905; FAX: 405271-8568; E-mail: Paul-Kincade@omrf.ouhsc.edu

Received for publication 20 May 1996 and accepted in revised form 30 May 1997.

J. Clin. Invest.

(c) The American Society for Clinical Investigation, Inc. 0021-9738/97/09/1227/13 \$2.00

Volume 100, Number 5, September 1997, 1217-1229

http://www.jci.org cell migration, pericellular matrix formation, lymphohematopoiesis, and the aggressive behavior of tumors (9, 11-13). Mechanisms involved in the latter remain unclear, but the density of CD44 and use of alternative mRNA splicing to express particular isoforms may be important prognostic indicators for some human malignancies (14). In some cases, the HA recognition function of CD44 can correspond in either a positive or negative way to the growth, invasion, and metastasis of experimental tumors (15-19).

Although CD44 is widely expressed as a surface protein, it is an active HA receptor on only certain cell types. As one example, resting $\mathrm{B}$ and $\mathrm{T}$ lymphocytes are CD44 positive, but do not bind to HA until the cells are activated (20-22).

Several mechanisms that are not mutually exclusive have been proposed through which this receptor function might be regulated $(10,20,23)$. They include physical interaction of CD44 with other intracellular and transmembrane proteins (24-27). This might lead in turn to local clustering of the receptor on the cell surface, and/or a conformational change to a ligand-binding state. Particular anti-CD44 antibodies artificially induce ligand binding on certain cell types, but the antibodies could mimic some naturally occurring substance which modulates CD44 functions $(28,29)$. Four recent studies demonstrated that posttranslational modifications of CD44 can also prevent the molecule from recognizing HA (30-33). A pair of Chinese hamster ovary $(\mathrm{CHO})$ cell tumors dramatically differed in this respect, and we speculated that a difference in $N$-glycosylation was particularly important (30). Additional glycosylation-disrupting treatments described here support that hypothesis, and we determined that the primary amino acid sequences of the proteins were identical. Soluble CD44 molecules prepared from these cells differed in terms of size and function attributable to glycosylation. Furthermore, biochemical analysis revealed that while CD44 made by both types of cells had highly branched, complex-type glycans, they were more highly sialylated on molecules made by the parent CHO-K1 cells.

We also show that the non-HA-binding $\mathrm{CHO}$ tumor is remarkably responsive to environmental conditions, as reduced glucose levels in culture and unknown signals in vivo reversibly induce HA recognition. Treatment with glycosylation inhibitors or glucose deprivation influenced the HA recognition function of CD44 expressed by many but not all of a series of transformed and normal cells. Posttranslational modifications

1. Abbreviations used in this paper: BZ $\alpha$ GalNAc, benzyl 2-acetamido-2-deoxy- $\alpha$-D-galactopyranoside; $\mathrm{CHO}$, Chinese hamster ovary; 2-DG, 2-deoxy-D-glucose; FL-HA, fluorescein-labeled hyaluronan; HA, hyaluronan; HPA, helix pomatia agglutinin; PNA, peanut agglutinin. 
of CD44 provide an important but not exclusive mechanism through which some cell interactions are regulated. These findings should be relevant to understanding the behavior of both normal and malignant cells.

\section{Methods}

Animals. Breeding pairs of $\mathrm{Bcl}-2$ transgenic mice were kindly provided by Dr. Andreas Strasser (Walter and Eliza Hall Institute, Melbourne, Australia), and CB17.SCID mice were derived from animals donated by Dr. Mel Bosma (Fox Chase Cancer Institute, Philadelphia, PA). Both colonies were maintained in our Laboratory Animal Resources Center.

Cells. Wild-type CHO (CHO-K1) cells (30), an HA-binding subclone of CHO cells (CHO-SKP) (30), the murine KLN205 squamous cell carcinoma (34), the murine B16-F10 melanoma (American Type Culture Collection, Rockville, MD), murine S17 stromal cells (35), and the murine Neuro-2a neuroblastoma (American Type Culture Collection) were cultured in MEM (GIBCO BRL, Grand Island, NY) with $10 \%$ FCS, L-glutamine, nonessential amino acids, $50 \mu \mathrm{M} 2-\mathrm{ME}$, and antibiotics. It is important to note that $\mathrm{CHO}$ cells distributed by the American Type Culture Collection (ATCC CCL-61) differ from the CHO-K1 cells used in our studies and constitutively recognize HA (our unpublished observations). The murine WEHI $231 \mathrm{~B}$ lymphoma, 7OZ/3 pre-B lymphoma, GM86 erythroleukemia, and L cell fibroblast lines were maintained in RPMI 1640 with L-glutamine, 2-ME, $10 \%$ FCS, and antibiotics (complete RPMI). Two IL-7-dependent pre-B cell clones, D6 and F10, were derived from the bone marrow of a Bcl-2 transgenic mouse and maintained in complete RPMI with IL-7 (30). $\mathrm{Ba} / \mathrm{F} 3$ pro-B cells (36) were maintained in complete RPMI with $5 \%$ WEHI-3 cell-conditioned medium (IL-3-rich). A non-HA-binding subclone of the murine WB lymphoma (WB-N, isolated from a line originally provided by Dr. Jayne Lesley, The Salk Institute, San Diego, CA) (29), P815 mastocytoma, J774A.1 monocyte-macrophage, and WEHI-3 myelomonocyte cells were maintained in Dulbecco's MEM (DMEM) with 10\% FCS and 2-ME, L-glutamine, and antibiotics. The murine EL-4 T lymphoma was maintained in DMEM with $10 \%$ horse serum, and the murine G7 tumorigenic myoblast was maintained in DMEM with $10 \%$ FCS plus $10 \%$ horse serum.

Reagents. 2-deoxy-D-glucose (2-DG), benzyl 2-acetamido-2-deoxy$\alpha$-D-galactopyranoside (BZG $\alpha$ lNAc), neuraminidase (from Arthrobactor ureafaciens), keratanase (from Pseudomonas species), bovine testicular hyaluronidase, and streptomyces hyaluronidase were all purchased from Sigma Chemical Co. (St. Louis, MO). $\alpha$-D-glucose was from Aldrich Chemical Co. (Milwaukee, WI). Tunicamycin was from Calbiochem-Novabiochem Corp. (La Jolla, CA).

Reverse transcriptase $-P C R$ and sequencing. Poly $\mathrm{A}^{+}$RNA was isolated from CHO-K1 and -SKP cells using a Fast Track $^{\circledR}$ mRNA isolation kit (Invitrogen Corp., San Diego, CA). cDNA synthesis and PCR reactions were as described previously (34). PCR primers that we previously designated OM6AR and OM2AR and matched to the amino- and carboxy-terminal portions of hamster CD44 were used. The PCR products were cloned into the PCR II vector (Invitrogen Corp.) and sequenced with an Applied Biosystems 373 DNA sequencer (Perkin-Elmer, Norwalk, CT). Two independent clones were sequenced for each PCR product.

Transfections and preparation of soluble CD44-Ig. A construct containing the entire extracellular domain of the hematopoietic form of murine $\mathrm{CD} 44$ and the hinge, $\mathrm{CH} 2$, and $\mathrm{CH} 3$ regions of human $\mathrm{IgG}_{1}$ has been described (30). This was subcloned into the pcDNA3 vector (Invitrogen Corp.) and used to prepare stable transfectants of $\mathrm{CHO}$ cell subclones. Culture supernatants containing soluble CD44-Ig were harvested, and fusion proteins were purified using protein A columns (Pierce Chemical Co., Rockford, IL). The concentration of purified CD44-Ig was determined with a CD44-specific ELISA assay as described (37). Full-length cDNA for the hematopoietic form of murine CD44.1 in the $\mathrm{pRc} / \mathrm{RSV}$ vector (Invitrogen Corp.) was stably trans- fected into Neuro-2a cells, and expression levels of the introduced CD44 were confirmed by use of the allele-specific RAMBM44.5 CD44 antibody (generously provided by Dr. Jayne Lesley).

$H A$ recognition by CD44-Ig fusion proteins. Equal amounts of purified CD44-Ig fusion proteins were agitated with $6 \mu \mathrm{m}$ polystyrene beads (Polysciences, Inc., Warrington, PA) for $2 \mathrm{~h}$ at room temperature before blocking by incubation with $1 \%$ BSA in PBS for $1 \mathrm{~h}$. Separate aliquots of beads were washed and treated with either neuraminidase $(1 \mathrm{U} / \mathrm{ml})$ in $50 \mathrm{mM}$ sodium phosphate, $\mathrm{pH} 6.5$, overnight or keratanase $(1 \mathrm{U} / \mathrm{ml})$ in PBS for $1 \mathrm{~h}$ at $37^{\circ} \mathrm{C}$. The coated beads were then washed and exposed to the biotin-labeled anti-CD44 antibody KM81 followed by FITC-labeled avidin to assess amounts of CD44 immobilized. Separate aliquots of beads were exposed to graded concentrations of fluorescein-labeled HA (FL-HA) (30). Median fluorescence intensities of the beads were then determined by flow cytometry. The results were expressed as ratios of FL-HA bound/amounts of CD44 immobilized to normalize for small variations in amounts of CD44 coating.

Antibodies and flow cytometry. The $\mathrm{KM} 114\left(\mathrm{IgG}_{1}\right)$ and $\mathrm{KM} 81$ $\left(\mathrm{IgG}_{2 \mathrm{a}}\right) \mathrm{mAbs}$ recognize both murine and hamster CD44 (29). The IRAWB14 antibody to murine CD44, which enhances HA binding (20), was generously donated by Dr. Jayne Lesley. The KMI6 ( $\left.\operatorname{IgG}_{2 \mathrm{a}}\right)$ antibody (38) to $\beta_{1}$ integrin was used as an irrelevant isotypematched control. Goat anti-mouse IgM-PE was purchased from Southern Biotechnology, Inc. (Birmingham, AL). Cells were stained with FL-HA (36 $\mu \mathrm{g} / \mathrm{ml})$ (29) or FITC-conjugated peanut agglutinin (PNA, $3 \mu \mathrm{g} / \mathrm{ml}$; Vector Laboratories, Inc., Burlingame, CA) in FCS/ PBS $\left(3 \% \mathrm{FCS}, 0.1 \% \mathrm{NaN}_{3}\right)$ for $15 \mathrm{~min}$ at $4{ }^{\circ} \mathrm{C}$. In the blocking or enhancing experiments, cells were first exposed to KM81, KM114, or IRAWB14 antibodies for $15 \mathrm{~min}$, followed by staining with FL-HA. Drug-treated cells were stained with biotin-labeled Helix pomona agglutinin (HPA, Vector Laboratories, Inc.) for $15 \mathrm{~min}$, followed by FITC-avidin $(5 \mu \mathrm{g} / \mathrm{ml})$ (Zymed Laboratories Inc., South San Francisco, CA). The cells were washed three times with FCS/PBS and analyzed with a FACScan ${ }^{\circledR}$ (Becton Dickinson Immunocytometry Systems, Mountain View, CA). Numbers of viable B cells that either constitutively bound FL-HA or did so with preincubation with IRAWB14 antibody were determined. Dead cells were excluded from the analysis on the basis of propidium iodide staining, and B cells were selectively analyzed by staining with goat anti-mouse IgM-PE.

Glucose deprivation of $\mathrm{CHO}$ cells. Glucose-free DMEM and highglucose $(25 \mathrm{mM})$ DMEM were from GIBCO BRL. Control cultures of CHO-K1 cells were plated at $10^{6}$ cells per $100-\mathrm{mm}$ dish in the highglucose medium with $2 \%$ FCS, L-glutamine, nonessential amino acids, sodium pyruvate $(1 \mathrm{mM})$, and 2-ME. Parallel cultures were prepared with glucose-free DMEM with $2 \%$ FCS, L-glutamine, nonessential amino acids, sodium pyruvate $(1 \mathrm{mM})$, and 2-ME. Subgroups of cultures contained graded amounts of $\alpha$-D-glucose. Cells were usually cultured for $24 \mathrm{~h}$, harvested with EDTA, and stained with FL-HA with or without KM114 antibody before being analyzed by flow cytometry.

Time course of glucose deprivation of $\mathrm{CHO}-\mathrm{K} 1$ cells. $\mathrm{CHO}-\mathrm{K} 1$ cells were initially plated in complete MEM at $10^{6}$ cells per $100-\mathrm{mm}$ dish. After various intervals, subsets of cultured cells were washed twice with PBS before continuing culture in complete glucose-free DMEM without FCS or with $0.5 \%$ FCS. The cells were then harvested and tested for FL-HA binding by flow cytometry.

Glucose deprivation of cell lines. Each of the cell types listed in Table I were plated at $2 \times 10^{5}$ cells per $25-\mathrm{cm}^{2}$ flask in appropriate medium. After $1 \mathrm{~d}$ of culture, cells were washed twice with PBS and changed to fresh flasks containing either supplemented high-glucose DMEM with $0.5 \%$ FCS, or supplemented glucose-free DMEM with $0.5 \%$ FCS, and incubated for another day. The S17, Neuro-2a, and D6 cell lines were also treated with $500 \mathrm{U} / \mathrm{ml}$ bovine testicular hyaluronidase for $24 \mathrm{~h}$ to remove endogenous HA. All cells were harvested and tested for CD44 expression with the KM114 antibody, or constitutive and IRAWB14-enhanced FL-HA binding by flow cytometry. All experiments were repeated at least three times, and the values 
were averaged. When $0-10,10-50$, or $50-100 \%$ of cells exceeded the background level of staining, this was arbitrarily designated - \pm , or + , respectively, in Table I.

Treatment with glycosylation-inhibiting drugs. CHO-K1 cells were cultured in supplemented DMEM with or without $3 \mathrm{mg} / \mathrm{ml} 2-\mathrm{DG}$ overnight, or cultured in complete MEM with or without $16 \mathrm{mM} \mathrm{BZ} \alpha \mathrm{Gal}-$ NAc for $2 \mathrm{~d}$, before being analyzed for FL-HA and lectin binding.

Glucose deprivation and glycosylation inhibition of splenic $B$ cells. Single-cell suspensions were prepared from the spleens of Bcl-2 transgenic mice and $10^{7}$ cells were cultured in $100-\mathrm{mm}$ culture dishes with $0.5 \%$ FCS containing DMEM alone or with $3 \mathrm{mg} / \mathrm{ml} 2-\mathrm{DG}$. Other cultures received $0.5 \%$ FCS containing DMEM with $10 \mu \mathrm{g} / \mathrm{ml}$ tunicamycin, or $0.5 \%$ FCS containing glucose-free DMEM. Cells were analyzed after either 2 or $4 \mathrm{~d}$ of culture.

Immunoprecipitation and immunoblotting. To estimate molecular weights, samples of purified CD44-Ig fusion proteins $(20 \mathrm{ng})$ were separated by SDS-PAGE and transferred to nitrocellulose membranes (Pierce Chemical Co.). Proteins were then detected by immunoblotting with 1/2,000 diluted horseradish peroxidase-coupled goat anti-human IgG (Southern Biotechnology, Inc.) and the enhanced chemiluminescence system (Amersham Corp., Arlington Heights, IL). $\mathrm{CHO}-\mathrm{K} 1$ cells were cultured in glucose-free, high-glucose DMEM, or high-glucose DMEM with 2-DG, and CHO-SKP cells were grown in high-glucose medium for $1 \mathrm{~d}$ before extraction and immunoprecipitation of cell surface CD44 as described previously (30). In brief, live cells $\left(10^{7} / \mathrm{ml}\right)$ were incubated with $0.1 \mathrm{mg} / \mathrm{ml}$ sulfosuccinimidobiotin (Pierce Chemical Co.) in labeling buffer for $30 \mathrm{~min}$ at room temperature. Cells were then washed and lysed for $1 \mathrm{~h}$ at $4^{\circ} \mathrm{C}$. The detergentsolubilized supernatants were recovered after centrifugation and precleared with $40 \mu \mathrm{l}$ goat anti-rat IgG Sepharose 4B beads (Zymed Laboratories Inc.) conjugated with irrelevant control KMI6 ( $\left.\operatorname{IgG}_{2 \mathrm{a}}\right)$ $\mathrm{mAb}$, followed by immunoprecipitation with either $\mathrm{KM} 81\left(\mathrm{IgG}_{2 \mathrm{a}}\right)$ coated beads or KMI6 as a negative control. After extensive washing, proteins were analyzed by SDS-PAGE under reducing conditions, followed by transfer to a nitrocellulose membrane (Pierce Chemical Co.). After blocking, the membrane was incubated with streptavidinhorseradish peroxidase in PBS containing 1\% BSA and $0.05 \%$ Tween 20. The protein bands were detected with the enhanced chemiluminescence system (Amersham Corp.). Prestained and biotinylated molecular weight markers (Bio-Rad Laboratories, Hercules, CA) were used as standards.

$H A$ recognition by cells recovered from solid tumors. Cultured $\mathrm{CHO}-\mathrm{K} 1$ cells were harvested using $5 \mathrm{mM}$ EDTA, and $10^{6}$ cells were suspended in $100 \mu \mathrm{l}$ MEM before dorsal subcutaneous injection into SCID mice. Tumors were grown for $2-4 \mathrm{wk}$ before excision and dispersal into single-cell suspensions. Cells were treated with either bovine testicular hyaluronidase $(500 \mathrm{U} / \mathrm{ml})$ or streptomyces hyaluronidase $(10 \mathrm{U} / \mathrm{ml})$ in PBS for $1 \mathrm{~h}$ at $37^{\circ} \mathrm{C}$. Two-color flow cytometry and the RAMBM44.5 mAb (specific for murine CD44) were then used to exclude murine cells and selectively enumerate hamster cells capable of binding FL-HA.

Metabolic radiolabeling of $\mathrm{CD} 44$ from $\mathrm{CHO}$ cell lines. $\mathrm{CHO}-\mathrm{K} 1$ and -SKP cells were metabolically radiolabeled for $72 \mathrm{~h}$ in complete $\alpha$-MEM containing $0.2 \mathrm{mCi} / \mathrm{ml}$ of $\mathrm{D}-\left[6-{ }^{3} \mathrm{H}\right]$ glucosamine $\left({ }^{3} \mathrm{H}-\mathrm{GlcN}\right)$ (20-40 Ci/mmol; DuPont-NEN, Boston, MA) (39). After labeling, the cells were harvested, lysed, and immunoprecipitated with KM81 anti-CD44 mAb, as described elsewhere, and the immunoprecipitates were analyzed by SDS-PAGE in $7.5 \%$ acrylamide. The gels were treated with $\mathrm{EN}^{3} \mathrm{HANCE}$, dried, and exposed overnight to $\mathrm{x}$-ray film. The region of each lane containing the single band of ${ }^{3} \mathrm{H}-\mathrm{GlcN}-$ labeled CD44 was identified and excised from the dried gel. The gel slice was incubated with Pronase (Calbiochem-Novabiochem Corp.) at $10 \mathrm{mg} / \mathrm{ml}$ overnight at $60^{\circ} \mathrm{C}$ in $0.1 \mathrm{M}$ Tris- $\mathrm{HCl}, \mathrm{pH} 8.0$. The digested samples were boiled for $30 \mathrm{~min}$, and the ${ }^{3} \mathrm{H}-\mathrm{GlcN}$-glycopeptides were desalted by chromatography on a column $(1 \times 50 \mathrm{~cm})$ of Sephadex G-10 in 7\% $N$-propanol in water. The desalted ${ }^{3} \mathrm{H}-\mathrm{GlcN}$-glycopeptides in the void fractions were pooled, dried by lyophilization, resuspended in deionized water, and stored at $-20^{\circ} \mathrm{C}$.
QAE-Sephadex column chromatography. The ${ }^{3} \mathrm{H}-\mathrm{GlcN}$-glycopeptides were dissolved in $1.0 \mathrm{ml} 2 \mathrm{mM}$ pyridyl/acetate ( $\mathrm{pH}$ 5.5) and applied to a $1.5-\mathrm{ml}$ column of QAE-Sephadex where 2-ml fractions were collected. At pH 5.5, neutral glycopeptides are not bound by the support, whereas sialylated/sulfated glycopeptides are bound. A step gradient of increasing pyridyl/acetate of $25,86,173,247$, and $309 \mathrm{mM}$ was used to elute glycopeptides containing $-1,-2,-3,-4$, and -5 charges due to sialic acid, respectively (40). Radiolabeled glycopeptides were treated in $25 \mu 10.05 \mathrm{M}$ citrate buffer ( $\mathrm{pH} \mathrm{4.5)}$ with $10 \mathrm{mU}$ A. ureafaciens neuraminidase overnight at $37^{\circ} \mathrm{C}$. The samples were diluted in $2 \mathrm{mM}$ pyridyl/acetate, applied to the column of QAESephadex, and eluted as described above. Free ${ }^{3} \mathrm{H}$-sialic acid released by neuraminidase is recovered as a -1 species in the $25 \mathrm{mM}$ pyridyl/ acetate step elution.

\section{Results}

Structural characteristics of CD44 expressed by related tumor cell lines. We previously described a pair of closely related $\mathrm{CHO}$ cell lines that differ in ability to recognize HA (30). A number of observations indicated that posttranslational modifications of CD44 probably accounted for this difference, but some other explanations were not excluded. We have now performed reverse transcription-PCR analysis, subcloning, and complete sequencing of CD44 transcripts from CHO-K1 and -SKP cells (Methods). This revealed that the hematopoietic isoform was the principal species of CD44 expressed by both cells, and that the cDNA sequences were identical. Each cell line similarly expressed small amounts of two larger transcripts that presumably represented minor splice variants.

We then expressed soluble CD44-Ig fusion proteins in this pair of cells to exclude the possibility that differences in other proteins determined ligand binding. The parent $\mathrm{CHO}-\mathrm{K} 1$ line does not bind HA, and purified soluble CD44-Ig made by these cells failed to bind HA when immobilized on a bead (Fig. $1 A$ ). In contrast, soluble CD44-Ig displayed substantial HAbinding activity when it was expressed in the CHO-SKP clone, which recognizes this ligand with its endogenous surface receptor. As in our previous studies (30), the HA recognition by intact CHO-SKP cells was totally blocked (typically $96 \%$ inhibition) with an mAb to CD44. The endogenous CD44 made by CHO-SKP cells was found previously to be slightly smaller (by $4 \mathrm{kD}$ ) than that made by wild-type CHO-K1 cells (30), and the same small size difference was apparent with soluble CD44-Ig (Fig. $1 \mathrm{~B}$ ). Treatment of soluble CD44-Ig from CHO-K1 cells with neuraminidase markedly induced ligand-binding ability (Fig. $1 \mathrm{~A}$ ). This demonstrates structural integrity of the molecule and strongly suggests that posttranslational modification accounts for its inability to recognize HA. A recent study of colon carcinoma cells indicated that keratan sulfate addition can negatively regulate CD44 function (33). However, CD44Ig made by CHO-K1 cells was unaffected by keratanase treatment (not shown).

CHO-K1 and -SKP cells were then metabolically radiolabeled with ${ }^{3} \mathrm{H}$-glucosamine and the ${ }^{3} \mathrm{H}-\mathrm{GlcN}$-labeled CD44 was immunoprecipitated and purified by SDS-PAGE and identified by autoradiography. Cells take up the ${ }^{3} \mathrm{H}$-glucosamine from the media and metabolize it to UDP- ${ }^{3} \mathrm{H}-\mathrm{GlcNAc}$, UDP $-{ }^{3} \mathrm{H}-\mathrm{GalNAc}$, and CMP_${ }^{3} \mathrm{H}-\mathrm{NeuAc}$, thereby allowing the specific radiolabeling of these sugar moieties on newly synthesized glycoproteins (41). ${ }^{3} \mathrm{H}-\mathrm{GlcN}$-glycopeptides were prepared by treatment of the gel slices containing CD44 with Pronase. None of the glycopeptides from CD44 derived from 
either cell line were bound by a column of Con A-Sepharose (data not shown). Con A-Sepharose binds well to $N$-glycans containing complex-type diantennary structures and high mannose-type structures, but the lectin does not bind to more highly branched complex-type tri-/tetraantennary $\mathrm{N}$-glycans (42). These results demonstrate that the $N$-glycans of CD44 are highly branched complex-type and that there are no obvious differences in the degree of branching of the $N$-glycans in the CD44 from either cell type.

The Pronase-derived ${ }^{3} \mathrm{H}$-GlcN-glycopeptides were analyzed for their degree of sialylation by ion exchange chromatography on a column of QAE-Sephadex. In this analysis at $\mathrm{pH}$ 5.5, glycopeptides lacking sialic acid are neutral species not bound by the support, whereas sialic acid-containing glycopeptides are bound and can be separated by their sialic acid content through a step elution with increasing concentrations of pyridyl/acetate. The results in Fig. 2 show that ${ }^{3} \mathrm{H}-\mathrm{GlcN}-$ glycopeptides in CD44 from CHO-K1 cells are more highly sialylated than those from CHO-SKP cells. The glycopeptides containing three sialic acids represented nearly $20 \%$ of the ${ }^{3} \mathrm{H}-\mathrm{GlcN}$-glycopeptides from CHO-K1 cells, whereas these glycopeptides represent $<10 \%$ of the total from CHO-SKP cells. In addition, there was an increase in glycopeptides containing two sialic acids in CD44 from CHO-SKP cells compared to the glycopeptides from CHO-K1 cells.

To further assess potential differences in sialylation, the ${ }^{3} \mathrm{H}-\mathrm{GlcN}$-glycopeptides from both cell types were treated with neuraminidase, as described in Methods, and the treated glycopeptides were analyzed by chromatography on QAE-Sephadex (Fig. 2). After treatment, the ${ }^{3} \mathrm{H}-\mathrm{GlcN}$-glycopeptides were converted to neutral species, demonstrating that all charge on the glycopeptides is due to sialic acid. The released free ${ }^{3} \mathrm{H}$-sialic acid was recovered in the $25 \mathrm{mM}$ pyridyl/acetate elution. The amounts of total radioactivity recovered as ${ }^{3} \mathrm{H}$-sialic acid in CD44 from CHO-K1 versus -SKP cells were 31 and $24 \%$, respectively (Fig. 2). These results, taken together with the results of ion exchange chromatography of the intact glyco- peptides, confirm that the glycans in $\mathrm{CD} 44$ from $\mathrm{CHO}-\mathrm{K} 1$ cells are more highly sialylated than those in CD44 from -SKP cells.

We conclude from these experiments that CD44 molecules produced by this pair of HA recognizing and nonrecognizing cells are functionally different, but not because of variations in the protein core. Larger and more heavily sialylated species of CD44 made by the CHO-K1 line have reduced ability to interact with HA.

Glycosylation inhibitors induce the HA recognition function of $\mathrm{CD} 44$. We found previously that exposure of $\mathrm{CHO}-\mathrm{K} 1$ cells to tunicamycin increased their ability to bind HA (30). This drug inhibits the first step in assembly of dolichol diphosphate-bound oligosaccharides and thus reduces $N$-glycosylation (43). Additional glycosylation disrupting agents were used to learn about other perturbations that influence the receptor and assess the relative importance of $O$-glycosylation. Overnight treatment with 2-DG resulted in HA recognition by CHO-K1 cells, and the importance of CD44 for binding was confirmed by use of the KM81 mAb (Fig. 3). The inhibitory action of 2-DG is thought to be complex, and multiple steps in oligosaccharide biosynthesis and attachment to protein may be affected $(44,45)$. As was previously the case with tunicamycin treatment (30), a substantial amount of ligand-binding ability was induced, even though only some of the CD44 molecules were converted to smaller sizes (see Fig. 8). This presumably means that fully glycosylated species do not interfere with neighboring CD44 molecules which have less carbohydrate.

Staining with particular mAbs also reflects drug-induced changes in the CD44 molecule. Tunicamycin treatment of CHO-K1 cells abolishes expression of the epitope detected by our KM201 antibody and reduces staining by the KM81 and KM114 antibodies $(29,30)$. The recognition of 2-DG-treated cells by KM81 was only slightly reduced, and the antibody blocked ligand recognition by $98 \%$ (data not shown and Fig. 3 ). However, the drug reduced staining by KM114 even more, and this antibody consequently had little influence on HA binding. There was no staining of cells treated with 2-DG by
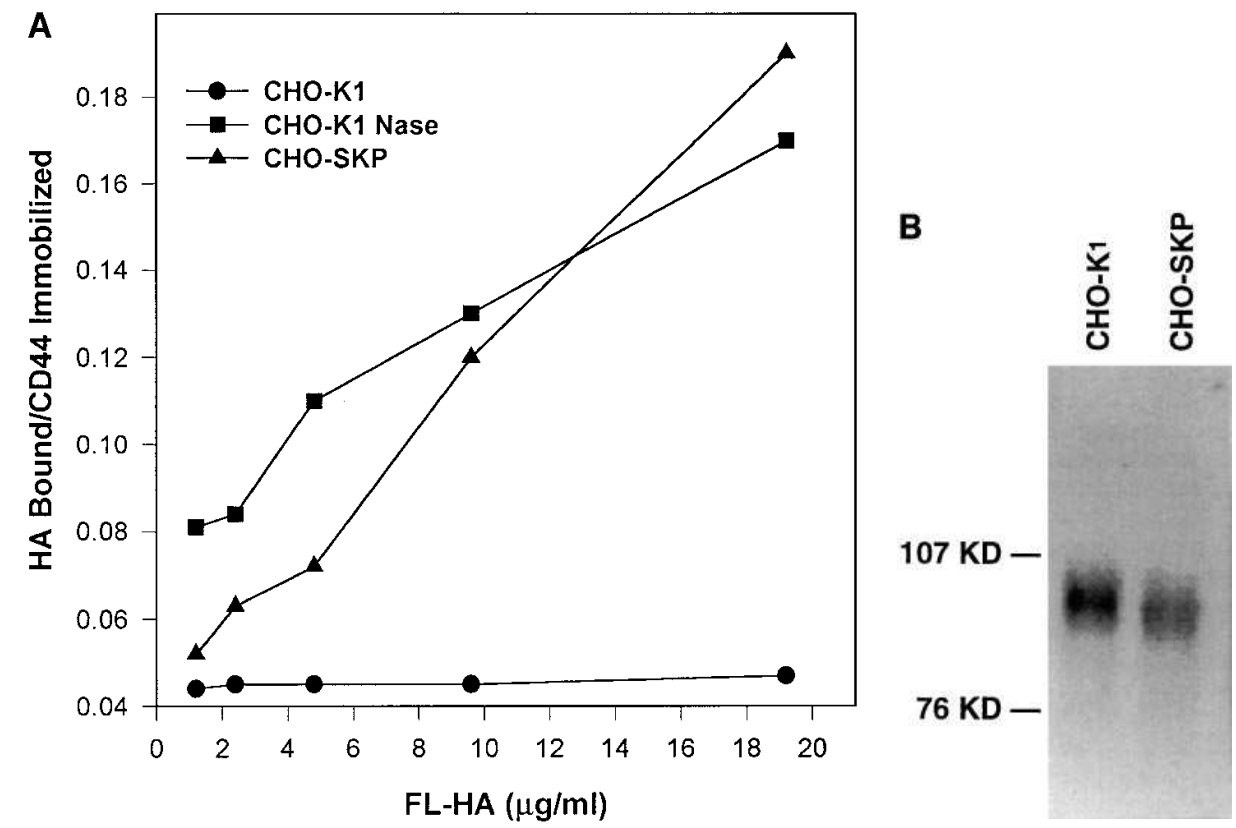

Figure 1. Intrinsic differences in soluble CD44-Ig fusion proteins made by closely related tumor cell clones. $(A)$ Soluble proteins purified from the medium of transfected CHO-K1 and -SKP cells were immobilized on polystyrene beads. Aliquots of the protein made by CHO-K1 cells were neuraminidase (Nase) treated as indicated. Amounts of bound CD44 protein were assessed by staining with the KM81 antibody and found to be similar (not shown). Relative abilities to bind FL-HA presented over a range of concentrations were determined by flow cytometry and expressed as a ratio of HA bound (median fluorescence intensity) to immobilized CD44 (see Methods). The data are representative of three independent experiments. (B) The apparent sizes of CD44-Ig proteins were evaluated by SDS-PAGE as detailed in Methods. 


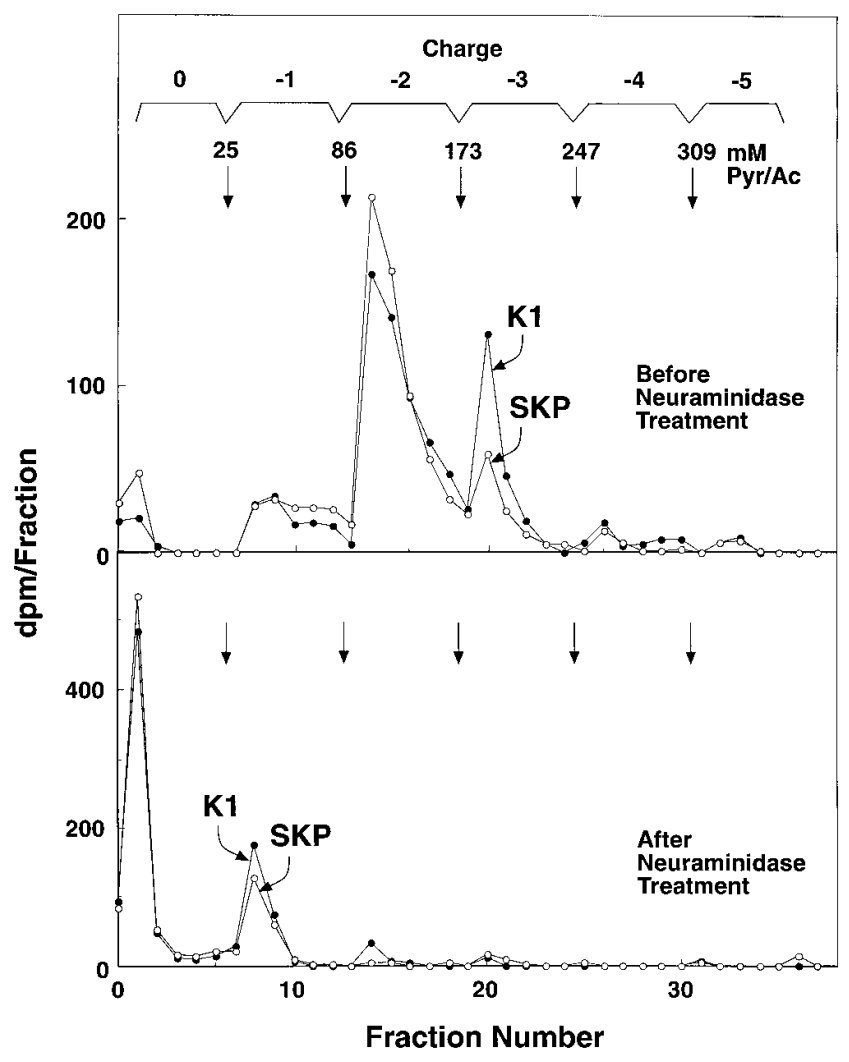

Figure 2. QAE-Sephadex column chromatography of ${ }^{3} \mathrm{H}-\mathrm{GlcN}$-glycopeptides from CD44 derived from CHO-K1 and -SKP cells before and after treatment with neuraminidase. (Top) The ${ }^{3} \mathrm{H}-\mathrm{GlcN}$-glycopeptides were applied to a column of QAE-Sephadex in $2 \mathrm{mM}$ pyridyl/acetate ( $\mathrm{pH}$ 5.5), as described in Methods, and bound glycopeptides were eluted with a step gradient of pyridyl/acetate, as indicated in the top panel. Glycopeptides with increasing negative charges, i.e., degree of sialylation, are eluted as shown. (Bottom) The ${ }^{3} \mathrm{H}-\mathrm{GlcN}$-glycopeptides were treated with neuraminidase, as described in Methods, and the treated glycopeptides were analyzed by chromatography on QAE-Sephadex. The resultant neutral glycopeptides are not bound by the column, whereas free ${ }^{3} \mathrm{H}$-sialic acid released by the neuraminidase is eluted with $25 \mathrm{mM}$ pyridyl/acetate.

the KM201 antibody. Therefore, treatment with this agent induced structural alterations in CD44 which include at least one glycosylation-dependent epitope.

A modest increase in HA recognition was observed after exposure of $\mathrm{CHO}-\mathrm{K} 1$ cells for $2 \mathrm{~d}$ with $\mathrm{BZ} \alpha \mathrm{GalNAc}$ (Fig. 4). This drug blocks elongation of $O$-glycans on glycoproteins and causes accumulation of $O$-glycans having only GalNAc linked to Ser/Thr residues (46). After exposure to BZ $\alpha$ GalNAc, only half of the cells had above-background staining with FL-HA and bound much less ligand than cells treated with 2-DG. This small degree of recognition was CD44 dependent, because it was again blocked by preexposure of cells to a CD44 antibody (data not shown). Fluorescent lectins were used to establish that $\mathrm{BZ} \alpha$ GalNAc markedly influenced glycosylation by $\mathrm{CHO}-$ K1 cells. HPA recognizes terminal $\alpha$-linked GalNAc, and staining with HPA increased after BZ $\alpha$ GalNAc treatment. More dramatic increases were observed in PNA staining. This lectin recognizes both the disaccharide Gal $\beta 1 \rightarrow 3 \mathrm{GalNAc}$ and terminal GalNAc, which occurs on $O$-glycans normally expressed by
CHO cells $(47,48)$. PNA reactivity is only observed when $O$-glycans are incompletely sialylated. Thus, while $O$-glycans may influence $\mathrm{CD} 44$ function on $\mathrm{CHO}-\mathrm{K} 1$ cells, their importance is much less than that attributable to $N$-glycans.

HA-recognizing cells are present within $\mathrm{CHO}$ cell tumors grown in vivo. The cultured $\mathrm{CHO}-\mathrm{K} 1$ cell line expresses surface CD44, but does not use it for recognition of HA (30). Tumors grown in situ are subject to many environmental conditions that might influence CD44-mediated HA recognition. Therefore, we prepared cell suspensions from solid CHO-K1 cell tumors grown in immunodeficient SCID mice and subsequently removed associated HA by treatment with hyaluronidase (see Methods). Mouse but not hamster cells stain with the RAMBM44.5 mAb to CD44 (29), and this provided a means for discriminating tumor from host cells. CHO-K1 cells comprised at least $64 \%$ of these single cell suspensions, and two-color flow cytometry was used to determine that a majority of them recognized FL-HA (an average of 59\% in three experiments, Fig. 5). This would be an underestimate if any hamster cells had HA not removed by enzyme treatment, or if the tumors were infiltrated with murine cells that had either shed or failed to express CD44. Thus, a tumor cell line that failed to recognize HA when grown in culture did so after forming a solid tumor. Essentially all HA binding was CD44 dependent and blocked $99 \%$ by treatment with the KM $81 \mathrm{mAb}$ (data not shown). Tumor cells that recognized FL-HA were purified by cell sorting, and these lost HA-binding ability within $1 \mathrm{~d}$ after being returned to culture. Thus, environmental signals delivered to solid tumors can markedly and reversibly influence this CD44-mediated function.

Exogenous glucose levels influence $\mathrm{HA}$ recognition in $\mathrm{CHO}$ cells. Glycosylation by $\mathrm{CHO}$ cells has been reported to be sensitive to exogenous glucose concentrations (49), and we have now determined that this dramatically influences HA recognition (Fig. 6). Glucose deprivation can interfere with the biosynthesis of lipid-linked oligosaccharide precursors, resulting in decreased $N$-glycosylation of proteins $(45,50)$. More than $93 \%$ of $\mathrm{CHO}-\mathrm{K} 1$ cells bound FL-HA when glucose was reduced to $25 \%$ of that typically present in tissue culture medium (1 g/liter, $5.6 \mathrm{mM}$ in MEM). This HA recognition was

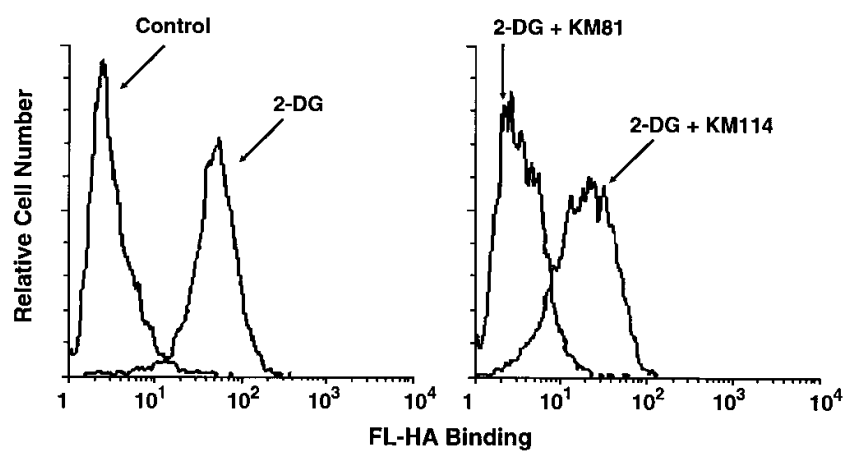

Figure 3. Treatment of parental CHO-K1 cells with a glycosylation inhibitor induces CD44-mediated HA recognition. Tumor cells were incubated with 2-DG or medium overnight, and FL-HA recognition was assessed by flow cytometry (left). While both KM81 and KM114 antibodies stain control CHO cells (not shown), only the KM81 antibody efficiently recognized CD44 on drug-treated cells and completely blocked ligand-binding ability (right). 


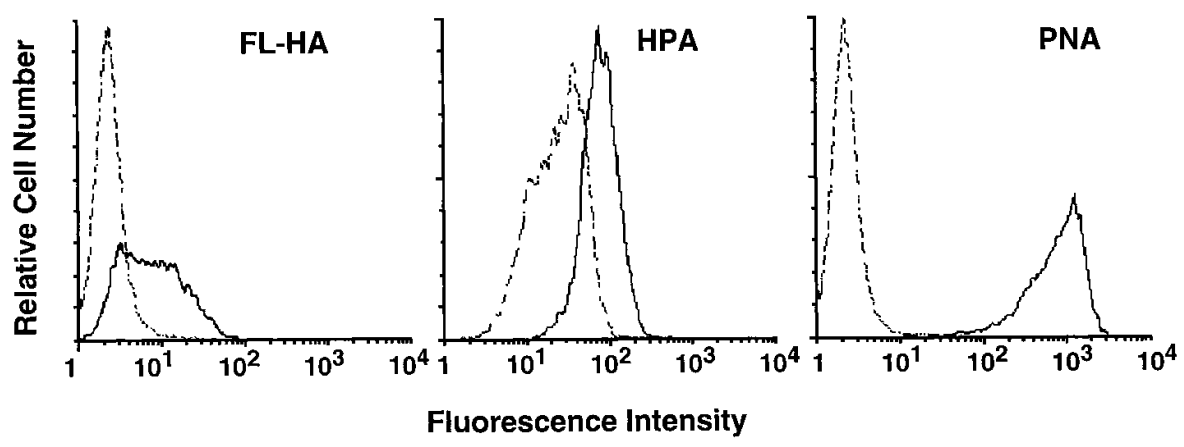

Figure 4. An inhibitor of $O$-glycan elongation has a moderate influence on HA recognition by CHO-K1 cells. Tumor cells were cultured in medium alone (dotted line) or with $\mathrm{BZ} \alpha \mathrm{GalNAc}$ (solid line) for $48 \mathrm{~h}$ before assessment of FL-HA binding by flow cytometry $(l e f t)$. The influence of the drug was also monitored by staining with fluorescent lectins (center and right).

CD44 dependent and completely sensitive (reduced to $2 \%$ or less ligand-binding cells) to the KM114 mAb. The appearance of active receptors was most rapid when FCS was omitted from the medium, possibly because it contributed some glucose (Fig. $7 A$ ). In this circumstance, HA-binding cells were detectable within $6 \mathrm{~h}$ of glucose deprivation, whereas $12 \mathrm{~h}$ were required to document a change when FCS was present. CHO$\mathrm{K} 1$ cells reverted to a non-HA-recognizing condition within $1 \mathrm{~d}$ when glucose was restored to the medium (Fig. 7 B). An adequate carbon supply was provided in these experiments by addition of sodium pyruvate (see Methods), and while cell growth was slowed, viabilities remained high. Although the morphology of CHO-K1 cells was not remarkably influenced by growth in low-glucose medium, the cells were much more easily detached than those maintained in conventional medium. HA-binding cells were observed in cultures of CHO-K1 cells maintained without medium change for $5 \mathrm{~d}$, and this may also reflect their sensitivity to exogenous glucose concentrations. It is important to note that the density of CD44 on $\mathrm{CHO}-\mathrm{K} 1$ cells was unaffected by any of these conditions (flow cytometry results not shown).

Cell surface labeling and immunoprecipitation were then used to evaluate the sizes of CD44 expressed by CHO-K1 cells that had been deprived of glucose or treated with 2-DG (Fig. 8 ). As in our previous study (30), the majority of CD44 was $\sim 90 \mathrm{kD}$ in size when cells were maintained in medium with high glucose. However, molecules of $\sim 70 \mathrm{kD}$ appeared on cells held for $24 \mathrm{~h}$ without glucose (Fig. 8). Separate aliquots of the treated cells were assessed for HA binding, and $>94 \%$ were positive. Thus, conversion of only a fraction of the CD44 to smaller size was needed for cells to recognize HA. An even greater degree of HA binding was observed in the same experiment when cells were treated with 2-DG, and this paralleled the appearance of a larger proportion of CD44 molecules of reduced size $(\sim 68 \mathrm{kD})$. For comparison, immunoprecipitation was also done in parallel with the CHO-SKP subclone, which constitutively binds HA (30). CD44 made by these cells is $\sim 4$ $\mathrm{kD}$ smaller than that expressed by control $\mathrm{CHO}-\mathrm{K} 1$ cells.

Induction of $H A$ recognition by normal $B$ lymphocytes. Normal lymphocyte populations differ with respect to CD44mediated HA recognition (10). While T cells lack this property, it is acquired by exposing them to particular mAbs (such as IRAWB14) $(20,29,51)$. Most B lymphocytes do not bind HA even in the presence of IRAWB14, and only a subpopulation does so after extended exposure to activation stimuli (30). The viability of normal lymphocytes is poor in extended culture, and this makes it difficult to evaluate their responsiveness to glycosylation inhibitors or glucose concentrations. We have now avoided that problem by using cells from mice transgenic for human Bcl-2. Transgenic B cells survive indefinitely in culture, and two-color flow cytometry was used to assess their ability to recognize FL-HA (Fig. 9). Approximately $1 \%$ of $\mathrm{B}$ cells bound HA when held for $48 \mathrm{~h}$ in conventional medium, and $<10 \%$ recognized ligand when they were exposed to the IRAWB14 antibody. In contrast, 22\% bound HA when cultured without glucose, and this recognition increased to $83 \%$ in the presence of IRAWB14. While these lymphocytes were virtually unaffected by tunicamycin treatment, a conspicuous population of IRAWB14-inducible cells appeared following treatment with 2-DG (Fig. 9). These experiments demonstrate that local glucose concentrations and certain glycosylationinhibiting drugs can influence the activity of CD44 on normal lymphocytes.

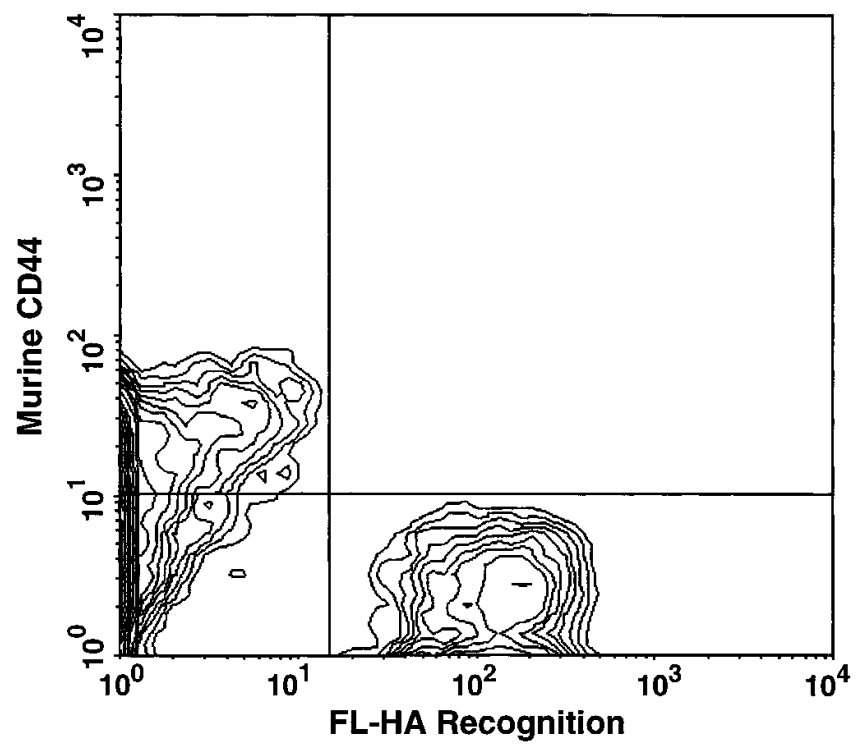

Figure 5. CHO-K1 cells recovered from solid tumors constitutively recognize HA. This is typical of the results of three independent experiments where tumors were grown in SCID mice for 2-4 wk, dissected, dissociated, and treated with hyaluronidase before evaluation by flow cytometry (Methods). The tumors were infiltrated with variable numbers of murine cells, which were discriminated with the RAMBM44.5 antibody that does not detect hamster CD44. In this example, $>59 \%$ of the CHO-K1 cells recognized FL-HA, and the CD44 dependence of this binding was established by separate pretreatment of tumor cells with the KM81 monoclonal antibody (not shown). 

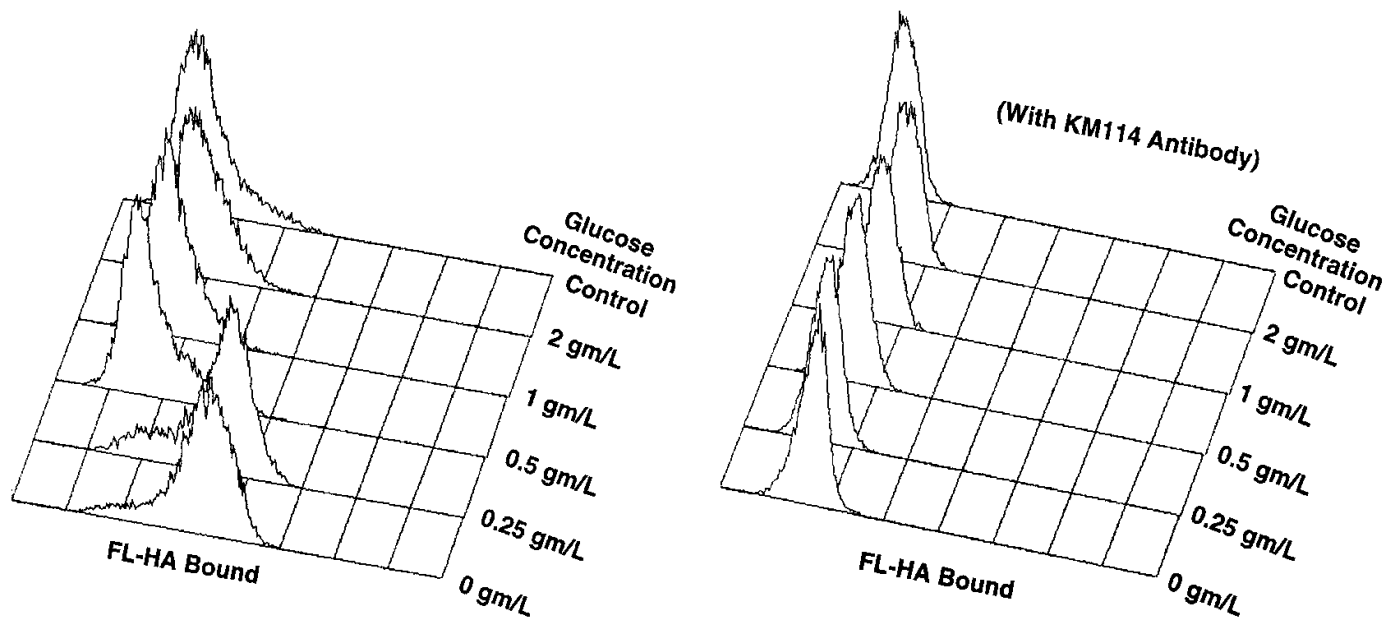

Figure 6. Glucose restriction induces CD44-mediated recognition of HA. $\mathrm{CHO}-\mathrm{K} 1$ cells were cultured for $24 \mathrm{~h}$ in high-glucose control medium $(4.5 \mathrm{~g} /$ liter glucose in DMEM with $2 \%$ FCS) or graded concentrations of $\alpha$-D-glucose in the same basic medium. Flow cytometry was then used to determine FL-HA binding, depicted on the $x$ axis in the left panel. The CD44 dependence of HA recognition was established by addition of monoclonal KM114 antibody (right).
Established cell lines are differentially influenced by glucose levels. A panel of cell lines was studied to determine if there are cell type-specific differences in sensitivity to exogenous glucose concentrations (Table I). One category of cells was similar to $\mathrm{CHO}-\mathrm{K} 1$ in that recognition of HA was dramatically increased after $24 \mathrm{~h}$ of culture in glucose-free medium (containing $0.5 \%$ FCS). This group included a transitional pre-B lymphoma (70Z/3), a mastocytoma (P815), a T lymphoma (WB-N), a stromal cell clone (S17), a macrophage tumor (J774A.1), a B lymphoma (W231), and a T lymphoma (EL4). The S17 stromal cell clone presumably produced HA, because it only bound FL-HA after pretreatment with hyaluronidase. Other members of this category only differed with respect to the degree of HA recognition, and there was no obvious correlation with amounts of CD44 expressed (data not shown). A weaker response to reduced glucose was observed with a second group of cell lines, which included a myelomonocytic leukemia (WEHI3), a myoblast (G7), a melanoma (B16-F10), an erythroleukemia (GM86), fibroblasts (L cells), and an IL-3dependent lymphoid cell line $(\mathrm{Ba} / \mathrm{F} 3)$. The marginal HA recognition achieved by glucose restriction was somewhat increased by exposure of the cells to the enhancing IRAWB14 antibody. Two IL-7-dependent lymphocyte clones (D6 and F10) and a neuroblastoma (Neuro-2a) were not obviously changed by growth without glucose, and only one of these even slightly recognized HA in the presence of IRAWB14.
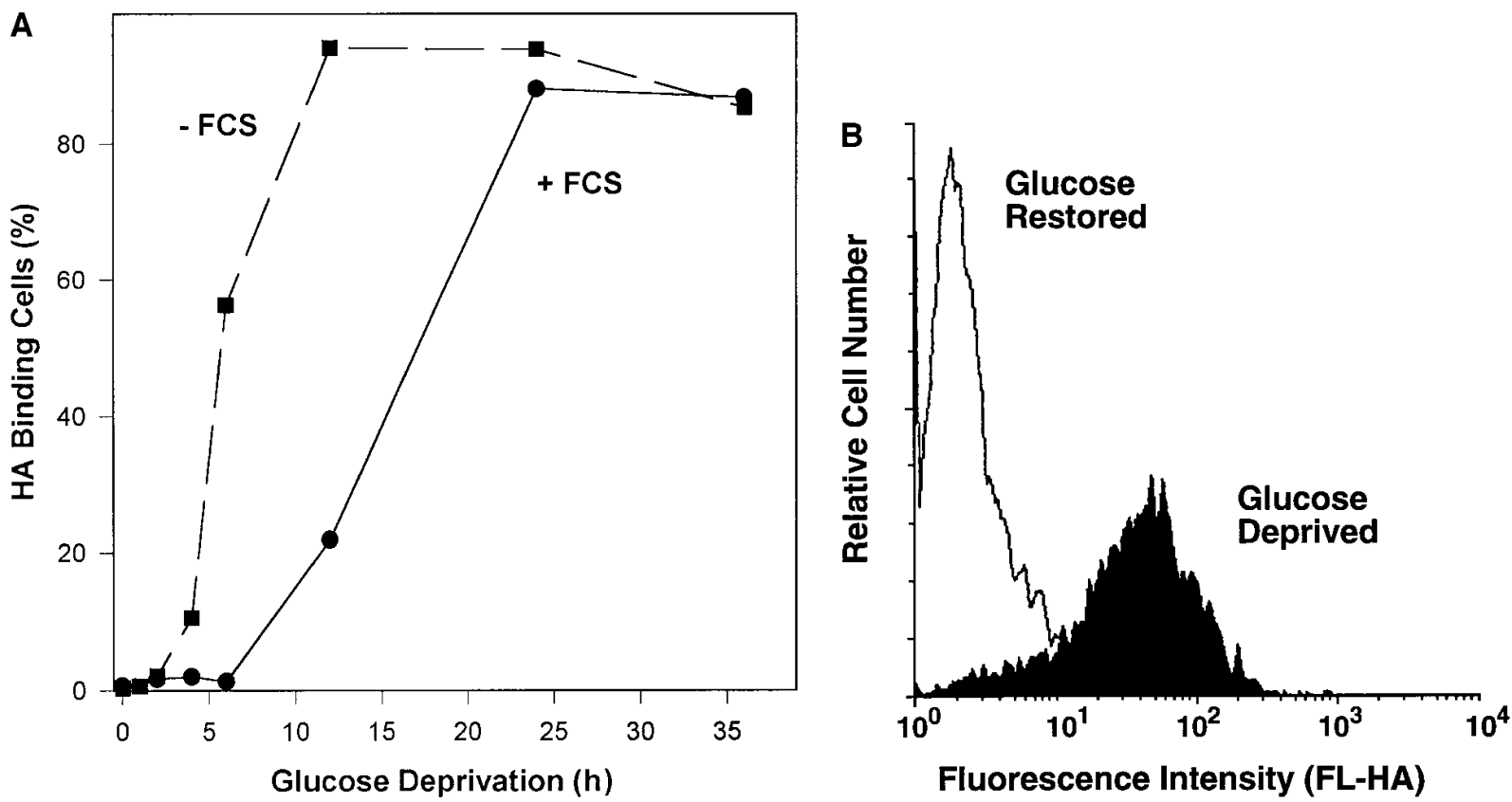

Figure 7. The kinetics of HA recognition by glucose-restricted tumor cells is influenced by FCS and is reversible. $(A) \mathrm{CHO}-\mathrm{K} 1$ cells were cultured in glucose-free DMEM without FCS or with $0.5 \%$ FCS. Percentages of cells that exceeded background levels of staining were determined by flow cytometry with FL-HA. (B) CHO-K1 cells that had been maintained without glucose for $24 \mathrm{~h}$ were returned to high-glucose medium for $24 \mathrm{~h}$ before analysis. 
A

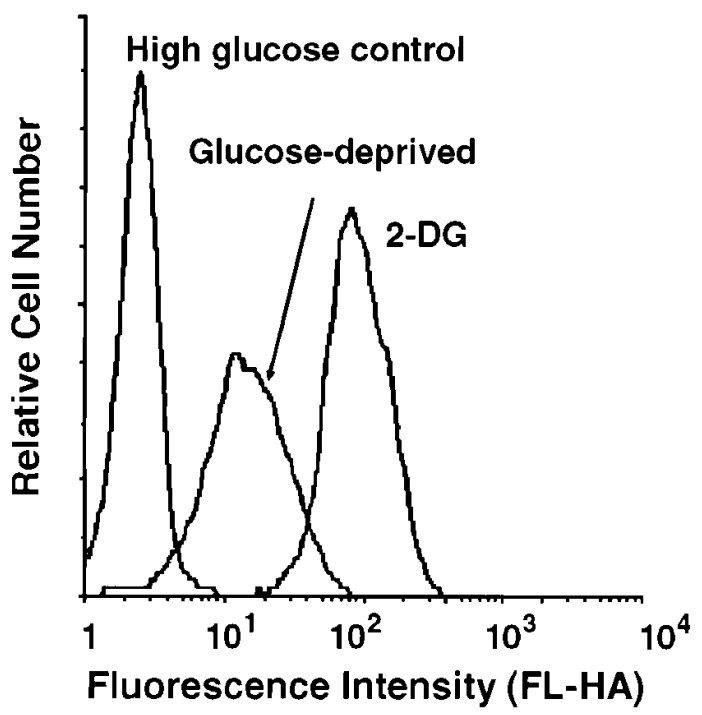

B

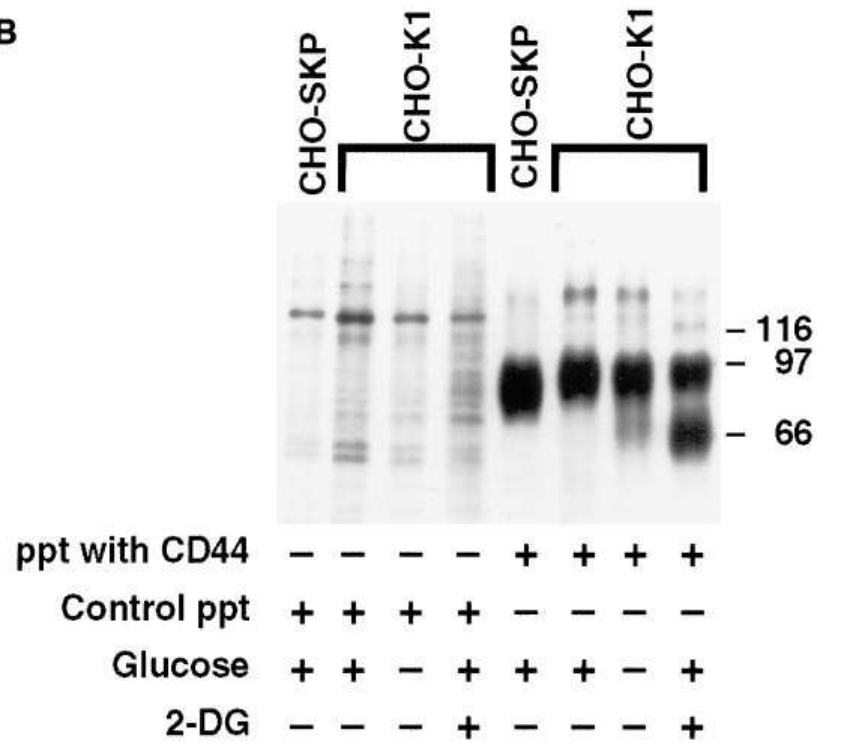

Figure 8. Comparison of the effects of glucose restriction and 2-DG treatment on HA recognition and CD44 size. CHO-K1 cells were cultured for $24 \mathrm{~h}$ in standard high-glucose-containing DMEM, glucosefree medium, or standard medium containing 2-DG. HA recognition is shown in $A$, and immunochemical evaluation of surface CD44 expressed by the same cells is shown in $B$. The CHO-SKP subclone constitutively binds HA and is included in this analysis for comparison.

One of the moderately responsive tumors (B16-F10) was found to bind HA after more prolonged ( $48 \mathrm{~h}$ ) incubation without glucose. This might suggest that the turnover of CD44 is relatively slow in this cell line, the cells express higher levels of glucose transporters, or that alteration of enzymes necessary for glycosylation requires time. It is interesting that the morphology of these melanoma cells was responsive to reduced glucose, and that cells at the end of the incubation were more rounded and heavily pigmented (not shown). The above experiments indicate that while glycosylation of CD44 may be a major factor in determining its ability to recognize HA, cells are not uniformly influenced by glucose deprivation, and additional mechanisms could be used to control the activity of this receptor.
Table I. Differential Sensitivity to Glucose Deprivation and Enhancing CD44 Antibody

\begin{tabular}{|c|c|c|c|}
\hline Cell line & Glucose & FL-HA & IRAWB14 + FL-HA \\
\hline \multirow[t]{2}{*}{ D6 } & + & - & - \\
\hline & - & - & - \\
\hline \multirow[t]{2}{*}{ Neuro-2a } & + & - & - \\
\hline & - & - & - \\
\hline \multirow{2}{*}{ F10 } & + & - & \pm \\
\hline & - & - & \pm \\
\hline \multirow[t]{2}{*}{ WEHI3 } & + & - & \pm \\
\hline & - & \pm & + \\
\hline \multirow[t]{2}{*}{ G7 } & + & - & \pm \\
\hline & - & \pm & + \\
\hline \multirow[t]{2}{*}{ B16-F10 } & + & - & \pm \\
\hline & - & \pm & + \\
\hline \multirow[t]{2}{*}{ GM86 } & + & - & + \\
\hline & - & \pm & + \\
\hline \multirow[t]{2}{*}{$\mathrm{L}$} & + & - & + \\
\hline & - & \pm & + \\
\hline \multirow[t]{2}{*}{$\mathrm{Ba} / \mathrm{F} 3$} & + & - & + \\
\hline & - & \pm & + \\
\hline \multirow[t]{2}{*}{$70 \mathrm{Z} / 3$} & + & - & + \\
\hline & - & + & + \\
\hline \multirow[t]{2}{*}{ P815 } & + & - & + \\
\hline & - & + & + \\
\hline \multirow[t]{2}{*}{ WB-N } & + & - & + \\
\hline & - & + & + \\
\hline \multirow[t]{2}{*}{ S17 (HASE RX) } & + & \pm & + \\
\hline & - & + & + \\
\hline \multirow[t]{2}{*}{ J774A.1 } & + & \pm & + \\
\hline & - & + & + \\
\hline \multirow[t]{2}{*}{ W231 } & + & \pm & + \\
\hline & - & + & + \\
\hline \multirow[t]{2}{*}{ EL4 } & + & \pm & + \\
\hline & - & + & + \\
\hline
\end{tabular}

All cells were cultured in DMEM medium with or without glucose for $24 \mathrm{~h}$. Cultures of S17 cells contained in addition bovine testicular hyaluronidase $(500 \mathrm{U} / \mathrm{ml})$. The cells were then harvested and analyzed for constitutive or IRAWB14-enhanced binding of FL-HA by flow cytometry. The results are summarized as,- \pm , or + when $0-10,10-50$, or 50 $100 \%$ of the cells bound this ligand.

Poor HA recognition by an introduced CD44 in neuronal cells. Alternative splicing of CD44 mRNA transcripts represents one of many mechanisms for regulation of $\mathrm{HA}$ recognition by CD44 (10). Furthermore, a unique splicing pattern was described previously for one neuroblastoma (52), providing a possible explanation for the unresponsiveness of Neuro-2a cells to glucose deprivation (Table I). We tested this hypothesis by introducing a wild-type hematopoietic form of CD44 cDNA into Neuro-2a cells. A polymorphism was exploited to distinguish recipient from donor-type CD44 and to monitor levels of cell surface expression in the resulting stable transfectants. This construct conferred constitutive HA-binding ability on $\mathrm{T}$ lymphoma cells, and the activity increased when transfected cells were exposed to the enhancing IRAWB14 antibody 


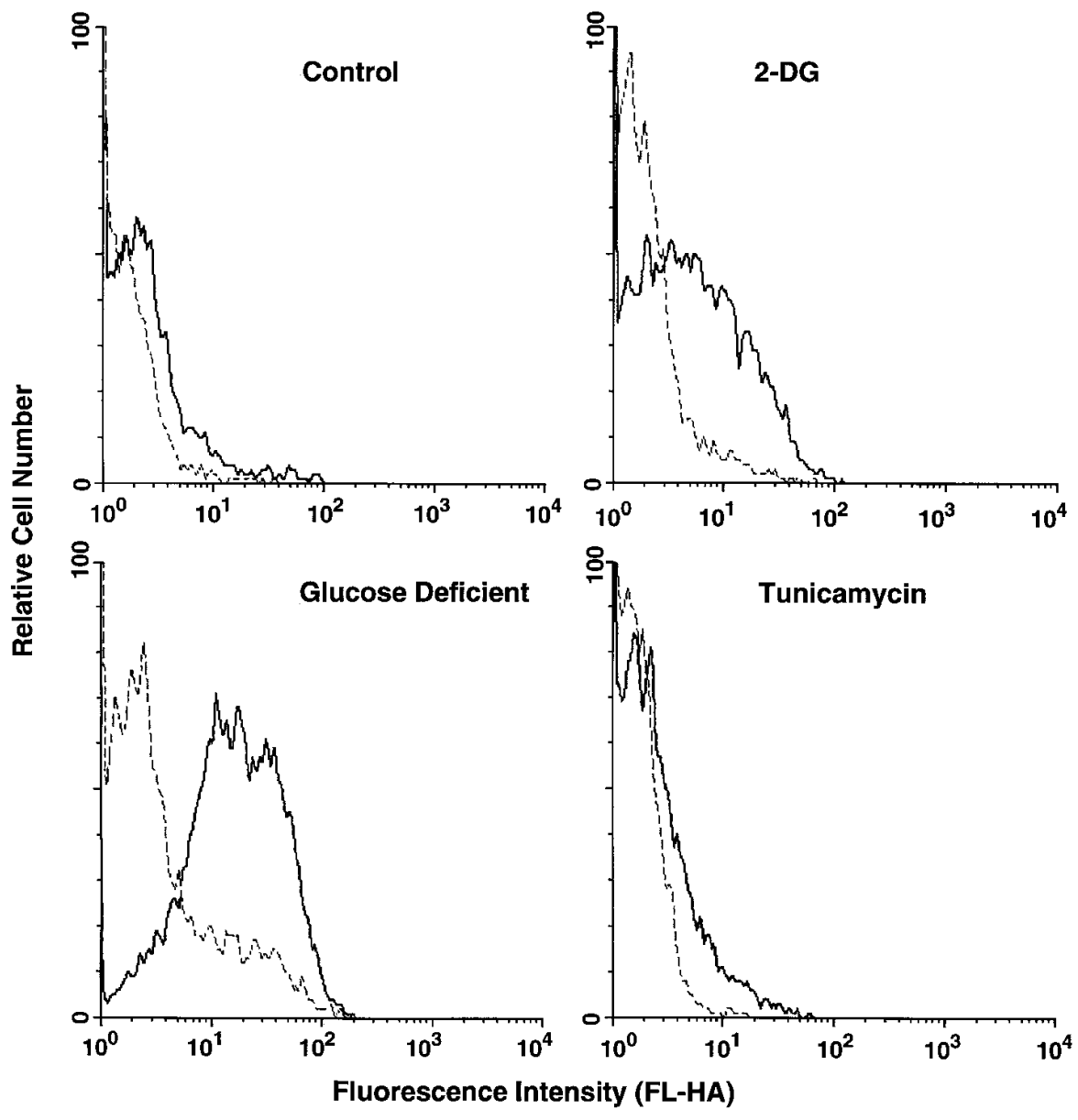

Figure 9. Treatments which influence glycosylation alter HA recognition by nontransformed B lymphocytes. Splenic $\mathrm{B}$ cells from Bcl-2 transgenic mice were maintained for $48 \mathrm{~h}$ in standard medium, in glucose-free medium, or with glycosylation-disrupting drugs as detailed in Methods. The cells were then stained with FL-HA alone (dotted line) or FL-HA in the presence of the enhancing IRAWB14 $\mathrm{mAb}$ (solid line). The histograms were gated to include only $\operatorname{sigM}^{+}$cells in the analysis.
(Fig. 10). In contrast, there was an extremely low level of HA recognition by transfected Neuro-2a cells that only increased slightly on exposure to the IRAWB14 antibody. Furthermore, neither constitutive nor IRAWB14-enhancing binding was influenced by glucose levels (Fig. 10). Therefore, something other than mutation or splicing of CD44 transcripts must account for the unresponsiveness of this tumor line to glucose deprivation. These findings indicate that multiple mechanisms exist for regulation of the HA receptor function of CD44. While it was markedly influenced by exogenous glucose levels in many cell types, this was not uniformly the case, and the molecule may be functionally inactive in tumors such as Neuro-2a for other reasons.

\section{Discussion}

This and other recent studies (30-33) reveal that glycosylation can negatively regulate the ligand-binding ability of CD44. The reversible ability of $\mathrm{CHO}$ cells to recognize $\mathrm{HA}$ when grown in vivo or in reduced glucose suggests that microenvironmental conditions in tissues may be significant for determining functions attributed to this molecule. It is important to note that while other cell surface molecules may recognize HA in some circumstances $(9,53-55)$, ligand binding by CHO cells was typically inhibited more than $95 \%$ by CD44-specific antibodies (30). Therefore, this tumor line represents an ideal model for investigating how structural modifications of a cell interaction molecule influence its HA recognition function. There is com- pelling evidence that $\mathrm{N}$-glycan addition and the degree of terminal sialylation are important for regulating the activity of CD44 on CHO cells. However, we also demonstrate substantial cell type-specific variability in the degree to which HA recognition can be induced by glycosylation inhibitors and reduced glucose. Thus, multiple mechanisms exist for controlling interactions between a widely distributed cell surface receptor and an equally abundant ligand.

A detailed analysis of CD44 glycoforms has not been reported. However, extensive glycosylation is indicated by the size of the most commonly expressed hematopoietic isoform $(90 \mathrm{kD})$ relative to the predicted size of the core protein $(42$ $\mathrm{kD}$ ) (for review see reference 10). There are five potential sites for $N$-glycan addition, and the protein is reduced to $\sim 58$ $\mathrm{kD}$ when $\mathrm{CHO}$ cells are treated with tunicamycin (30). The CD44 on CHO-K1 cells is converted to a ligand-binding state by this drug, which blocks an initial step in the assembly of dolichol diphosphate-bound oligosaccharides that are subsequently transferred to maturing proteins (43). However, it is not known whether all of the asparagine-containing motifs are used and exactly what carbohydrate structures are present. The hematopoietic isoform of CD44 also has 10 possible attachment sites for $O$-glycans, and still more are present in the larger CD44 isoforms. Enzymatic treatments suggest that these can be extensively used, and that $O$-glycosylation is very cell-type dependent $(32,56-59)$.

Ligand binding was also dramatically induced by treatment of CHO-K1 cells with 2-DG, and this corresponded to a reduc- 


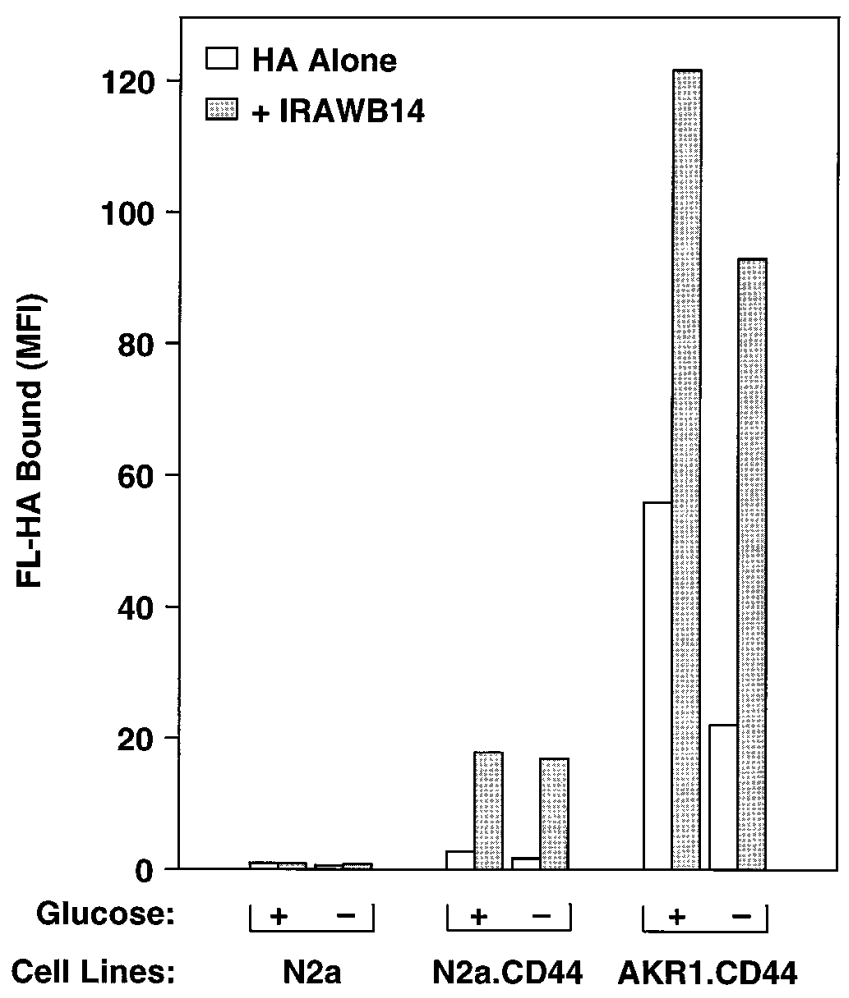

Figure 10. CD44-transfected neuroblastoma cells display little HA recognition. Stable transfectants of Neuro-2a cells were prepared and determined with an allele-specific antibody to express comparable amounts of CD44 to transfected AKR1 lymphoma cells (not shown). The cells were then evaluated for ligand recognition when grown in control or glucose-restricted medium, and with or without the enhancing IRAWB14 antibody.

tion in size of the major CD44 protein to $\sim 68 \mathrm{kD}$ (Fig. 8). This drug has a complex effect and may alter multiple steps in the biosynthesis of glycoprotein oligosaccharide units $(45,60)$. For example, it may inhibit the formation of dolichol-linked monosaccharide by trapping P-dolichol as Dol-PP-(GlcNAc) $)_{2}-2 \mathrm{DG}$, or block the assembly of lipid-linked oligosaccharides by incorporation of 2-DG instead of glucose or mannose (60).

Disruption of O-linked glycosylation by BZ $\alpha$ GalNAc only partially induced HA recognition by $\mathrm{CHO}-\mathrm{K} 1$ cells. However, $O$-glycosylation can be used by some cells to regulate CD44 function. Alternative splicing allows expression of variable CD44 exons in some cells, and the epithelial isoform of CD44 is known to include additional serine/threonine-rich regions. In recent studies by Bennett et al. (32), $O$-glycans had no influence on HA recognition by a soluble fusion protein containing the hematopoietic isoform of CD44. In contrast, a similar fusion protein made with the epithelial isoform of CD44 only bound this ligand when $O$-glycan elongation was inhibited. The modest influence of $O$-glycans to HA binding by CHO-K1 cells presumably reflects their predominant expression of the hematopoietic isoform of CD44. Similarly, Lesley and Hyman found that $\mathrm{BZ} \alpha \mathrm{GalNAc}$ had no effect on HA binding by lymphocytes (31). However, treatment with $\beta$-D-xyloside, which blocks addition of chondroitin sulfate and heparan sulfate side chains to proteins, conferred the ability to recognize HA in the presence of the IRAWB14 antibody. Takahashi and colleagues found recently that keratanase treatment increased the
HA-binding activity of colon carcinoma cells (33). The same enzyme had no effect on CD44-Ig made by CHO-K1 cells, presumably reflecting cell type-dependent variability in CD44 synthesis (see below). It is noteworthy that while glycosaminoglycan modification of CD44 negatively influences recognition of HA in some circumstances, it also confers on CD44 the ability to interact with the matrix ligands fibronectin and collagen $(61,62)$.

It has been proposed that carbohydrates on CD44 might restrict lateral mobility in the lipid bilayer, thus preventing high-density aggregates on the cell surface (31). However, ligand binding by purified CD44-Ig fusion proteins is markedly influenced by glycosylation (30, 32, 33, and this study). These experiments do not exclude the importance of CD44 interactions with other cellular proteins, or the glycosylation status of such proteins. However, they demonstrate that posttranslational modification of the CD44 molecule is sufficient to influence its function profoundly. We used this approach to show formally that CD44 made by a pair of closely related $\mathrm{CHO}$ cells differs in size and ligand-binding ability, although the protein cores are identical. Treatment of purified, inactive CD44Ig made by $\mathrm{CHO}-\mathrm{K} 1$ cells with neuraminidase substantially increased its ability to recognize HA. Moreover, we demonstrated that the membrane CD44 from CHO-K1 cells was more highly sialylated than that produced by the ligand-binding CHO-SKP cells.

This pair of cells provides an ideal model for further structure-function studies of CD44, especially within the context of a proposed three-dimensional structure of hyaladherins (63, 64). At least two sites for N-linked carbohydrate addition (asparagine- 82 and asparagine- 93 in the murine sequence) are located along the predicted HA-recognizing site of CD44. The first of these residues is particularly interesting because it is adjacent to an amino acid which differs between rat and mouse CD44 (Asp versus His at residue 83). The specificity of our ligand-blocking KM114 mAb is dependent on this residue as well as glycosylation of the protein $(29,30$, and this report). It will be important to learn if terminal sialic acids at those positions physically interfere with accessibility of the ligand to negatively charged CD44 residues.

Treatments which disrupted or altered glycosylation in CHO-K1 cells also influenced CD44-mediated HA recognition in other cell types, but to different degrees. This could in part be due to differences in rates of biosynthesis and/or mechanisms of glycosylation. For example, prolonged incubation without glucose was required for induction of HA binding by the B16-F10 tumor, and a slow turnover of glycoproteins in resting $\mathrm{B}$ lymphocytes might account for the minimal influence of tunicamycin treatment (Fig. 9). Constitutive HA recognition was not strongly induced in normal B lymphocytes by any of these treatments. However, the cells bound HA in the presence of the enhancing IRAWB14 antibody after culture in glucose-free medium or treatment with 2-DG. All of these findings indicate that alternative patterns of CD44 glycosylation may be used by different cell types, and an ultimate goal will be to define enzymes involved in posttranslational modification of CD44.

Our manipulations of normal and transformed cells resulted in either no influence on CD44 receptor activity, or gain of function. Treatment of purified CD44-Ig with neuraminidase markedly increased its recognition of HA (30). Furthermore, the glycosylation-defective Lec1, Lec2, and Lec8 vari- 
ants of CHO cells all constitutively bind HA via CD44 (30 and our unpublished observations). These and other recently published studies (31-33) are all consistent with a negative regulatory role for carbohydrate. In contrast, site-directed mutagenesis of glycosylation motifs and tunicamycin treatment were used in a recent study to argue that posttranslational modification is actually required for CD44 function (65). As pointed out by the authors, mutagenesis might result in loss of function through structural changes unrelated to carbohydrate. Technical differences in assays used to assess CD44 function might also be important. We measured staining of cells by highly purified FL-HA or interactions of CD44-Ig with HA immobilized on beads. Bartolazzi and colleagues (65) measured adhesion of transfected melanoma cells to HA-coated surfaces or CD44-Ig binding to tissue sections. We and others have noted differences in the dependence of CD44 on its cytoplasmic domain when soluble versus immobilized ligand is used to evaluate function $(11,20)$. Therefore, cell adhesion might be a more complex process than binding of soluble ligand. Regardless, Bartolazzi and colleagues also found that inhibition of complex oligosaccharide addition to CD44 by 1-deoxymannojirimycin treatment of melanoma cells increased CD44 function (65). Thus, posttranslational modification of CD44 may both negatively and positively influence its ligand-binding and adhesive functions.

Serglycin, osteopontin, and a subpopulation of invariant chain molecules appear to be additional ligands for CD44 (6668). Interactions of proteoglycan forms of CD44 with fibronectin and collagen have also been reported $(61,62)$. It will be important to learn if recognition of these molecules involves a common binding site, and whether these interactions are similarly regulated by CD44 glycosylation. We performed computer analysis of other hyaladherins and found one or more potential $\mathrm{N}$-glycosylation motifs in regions of neurocan, versican, aggrecan, brevican, and Tsg6a that are structurally homologous to CD44 (data not shown). The possibility should be investigated that posttranslational modifications influence interactions between these molecules and HA.

There may be mechanisms for controlling CD44 function that are unrelated to glycosylation. Neuro-2a cells were unresponsive to glucose restriction and did not bind HA even in the presence of the IRAWB14 antibody. Endogenous CD44 levels were low on this tumor, and a partial CD44 exon deletion had been described for another neuroblastoma (52). Therefore, the cells were stably transfected with CD44 to achieve a satisfactory level of expression and to negate the possibility of a structural abnormality in the CD44 molecule. Although a small degree of IRAWB14-inducible HA recognition was achieved, the tumor was still unresponsive to glucose restriction (Fig. 10). The intracellular portion of CD44 is important for effective binding of soluble HA, and phosphorylation of this domain can be critical to some but not all CD44 functions $(20,27,69)$. Furthermore, the molecule is thought to associate physically with transmembrane, cytoskeleton-associated, or other proteins (24-27). While it remains unclear how these interactions influence the function of CD44 (69), they may not involve glycosylation.

Antibodies can markedly influence the ligand-binding function of CD44 $(20,29)$. While some consistently block HA recognition, others only have this influence on particular cell lines. For example, the IRAWB14 antibody can dramatically increase ligand recognition by some cells, but it has minimal influence on resting B cells (reference 51 and Figs. 9 and 10), and an antibody with closely related specificity can actually block ligand binding (29). An understanding of these complex phenomena requires detailed information about the structure of CD44 and its carbohydrate modifications. However, antibodies which augment or block ligand binding by CD44 might do so by exposing or masking a binding site in a manner normally influenced by carbohydrate. In this regard, it is interesting that the epitope recognized by our KM201 antibody was lost and that ones detected by the KM114 and KM81 antibodies were diminished on cells treated with tunicamycin (30). Treatment with 2-DG also reduced CD44 recognition and activity of the first two antibodies, but had much less effect on the epitope recognized by the KM81 antibody. Alterations in glycosylation caused by glucose restriction did not influence the KM114 epitope (Fig. 6). Previous analysis of chimeric CD44 molecules suggested similarity or physical proximity of structures recognized by these three ligand-blocking antibodies (29). The present findings indicate that there may be subtle differences in dependence of CD44 epitopes on glycosylation. A similar conclusion has just been reported for some antibodies to human CD44 (65), and such reagents may prove useful as probes for glycosylation-dependent structural changes.

A number of experimental models have been used to demonstrate that CD44 can influence the growth and metastatic activity of malignant cells. While there are cell type-specific differences, and multiple mechanisms have been proposed, at least some of them involve expression of CD44, which is active as an HA receptor (15-18, 70). In this context, it is extremely interesting that $\mathrm{CHO}-\mathrm{K} 1$ cells acquired the ability to bind HA when grown in vivo, but lose this activity when returned to standard culture conditions. Glucose deprivation has been found previously to diminish posttranslational modification of proteins in several cell types $(49,71)$. Reduction of glucose to $25 \%$ of the standard concentration induced HA recognition by $\mathrm{CHO}-\mathrm{K} 1$ cells, and glucose restriction caused production of some CD44 molecules of lower molecular mass $(\sim 70 \mathrm{kD})$. Previous studies demonstrated a rapid reduction in the pool of lipid-linked $\mathrm{Glc}_{3} \mathrm{Man}_{9} \mathrm{GlcNAc}_{2}$ oligosaccharide in glucose-deprived CHO cells (49). This paralleled accumulation of $\mathrm{Man}_{5} \mathrm{GlcNAc}_{2}$ species and transfer of this smaller oligosaccharide to proteins. Our findings indicate that this alternate pathway may obviate the negative influence of glycosylation on CD44 function. Furthermore, these results raise the interesting possibility that variations in glucose concentrations in normal tissues or as a result of endocrine abnormalities might affect CD44-mediated cell adhesion and/or migration. Further study will be required to establish whether local glucose concentrations or some other aspect of the tumor environment induced HA recognition in CHO-K1 cells. However, the $250 \mu \mathrm{g} / \mathrm{ml}(1.4 \mathrm{mM})$ concentration of glucose that was effective is one that can be achieved in hypoglycemia or within tumors $(72,73)$. Interaction of cells with certain cytokines might have the opposite effect, i.e., reduce HA recognition via CD44. For example, TGF- $\beta_{1}$ and basic FGF caused increased glycosylation of the molecule in fibroblasts (74). Peripheral blood monocytes do not constitutively bind HA, but recently were demonstrated to acquire this function when placed in vitro (75). It will be important to learn how local tissue microenvironments influence receptor function on normal and transformed cells. Until those conditions can be reproduced, caution is advised in extrapolation from culture studies. 


\section{Acknowledgments}

The authors appreciate helpful comments on the manuscript by Dr. Jayne Lesley, Dr. Bob Hyman, Dr. Linda Thompson, Dr. Lisa Borghesi, and Dr. Kevin Moore. Dr. Anthony Day of Oxford University generously supplied molecular coordinates for hyaladherins, and Dr. Lief Hanson helped to evaluate three-dimensional relationships. Appreciation is also given to Dr. Shigeki Katoh, who initiated glycosylation studies in this laboratory and made suggestions on the manuscript.

This study was supported by grants AI-33085 and CA-37626 from the National Institutes of Health.

\section{References}

1. Zimmermann, D.R., and E. Ruoslahti. 1989. Multiple domains of the large fibroblast proteoglycan, versican. EMBO (Eur. Mol. Biol. Organ.) J. 8: 2975-2981.

2. Rauch, U., P. Gao, A. Janetzko, A. Flaccus, L. Hilgenberg, H. Tekotte, R.K. Margolis, and R.U. Margolis. 1991. Isolation and characterization of developmentally regulated chondroitin sulfate and chondroitin/keratan sulfate proteoglycans of brain identified with monoclonal antibodies. J. Biol. Chem. 266:14785-14801.

3. Doege, K.J., M. Sasaki, T. Kimura, and Y. Yamada. 1991. Complete coding sequence and deduced primary structure of the human cartilage large aggregating proteoglycan, aggrecan. J. Biol. Chem. 266:894-902.

4. Yamada, H., K. Watanabe, M. Shimonaka, and Y. Yamaguchi. 1994. Molecular cloning of brevican, a novel brain proteoglycan of the aggrecan/versican family. J. Biol. Chem. 269:10119-10126.

5. Deak, F., I. Kiss, K.J. Sparks, W.S. Argraves, G. Hampikian, and P.F. Goetinck. 1986. Complete amino acid sequence of chicken cartilage link protein deduced from cDNA clones. Proc. Natl. Acad. Sci. USA. 83:3766-3770.

6. Perides, G., W.S. Lane, D. Andrews, D. Dahl, and A. Bignami. 1989. Isolation and partial characterization of a glial hyaluronate-binding protein. $J$. Biol. Chem. 264:5981-5987.

7. Lee, T.H., H. Wisniewski, and J. Vilcek. 1992. A novel secretory tumor necrosis factor-inducible protein (TSG-6) is a member of the family of hyaluronate binding proteins, closely related to the adhesion receptor CD44. J. Cell Biol. 116:545-557.

8. Toole, B.P. 1990. Hyaluronan and its binding proteins, the hyaladherins. Curr. Opin. Cell Biol. 2:839-844.

9. Knudson, C.B., and W. Knudson. 1993. Hyaluronan-binding proteins in development, tissue homeostasis, and disease. FASEB (Fed. Am. Soc. Exp. Biol.) J. 7:1233-1241.

10. Lesley, J., R. Hyman, and P.W. Kincade. 1993. CD44 and its interaction with the extracellular matrix. Adv. Immunol. 54:271-335.

11. Thomas, L., H.R. Byers, J. Vink, and I. Stamenkovic. 1992. CD44H regulates tumor cell migration on hyaluronate-coated substrate. J. Cell Biol. 118: 971-977.

12. Miyake, K., K. Medina, S.-I. Hayashi, S. Ono, T. Hamaoka, and P.W. Kincade. 1990. Monoclonal antibodies to Pgp-1/CD44 block lympho-hemopoiesis in long-term bone marrow cultures. J. Exp. Med. 171:477-488.

13. Gunthert, U., M. Hofmann, W. Rudy, S. Reber, M. Zoller, I. Haubmann, S. Matzku, A. Wenzel, H. Ponta, and P. Herrlich. 1991. A new variant of glycoprotein CD44 confers metastatic potential to rat carcinoma cells. Cell. 65 : $13-24$.

14. Sherman, L., J. Sleeman, P. Herrlich, and H. Ponta. 1994. Hyaluronate receptors: key players in growth, differentiation, migration and tumor progression. Curr. Opin. Cell Biol. 6:726-733.

15. Bartolazzi, A., R. Peach, A. Aruffo, and I. Stamenkovic. 1994. Interaction between CD44 and hyaluronate is directly implicated in the regulation of tumor development. J. Exp. Med. 180:53-66.

16. Takahashi, K., I. Stamenkovic, M. Cutler, H. Saya, and K.K. Tanabe. 1995. CD44 hyaluronate binding influences growth kinetics and tumorigenicity of human colon carcinomas. Oncogene. 11:2223-2232.

17. Zahalka, M.A., E. Okon, U. Gosslar, B. Holzmann, and D. Naor. 1995. Lymph node (but not spleen) invasion by murine lymphoma is both CD44- and hyaluronate-dependent. J. Immunol. 154:5345-5355.

18. Zhang, L., C.B. Underhill, and L. Chen. 1995. Hyaluronan on the surface of tumor cells is correlated with metastatic behavior. Cancer Res. 55:428-433.

19. Driessens, M.H.E., P.J.M. Stroeken, N.F.R. Erena, M.A. Van der Valk, E.A.M. Van Rijthoven, and E. Roos. 1995. Targeted disruption of CD44 in MDAY-D2 lymphosarcoma cells has no effect on subcutaneous growth or metastatic capacity. J. Cell Biol. 131:1849-1855.

20. Lesley, J., Q. He, K. Miyake, A. Hamann, R. Hyman, and P.W. Kincade. 1992. Requirements for hyaluronic acid binding by CD44: a role for the cytoplasmic domain and activation by antibody. J. Exp. Med. 175:257-266.

21. Murakami, S., K. Miyake, C.H. June, P.W. Kincade, and R.J. Hodes.
1990. IL-5 induces a Pgp-1 (CD44) bright B cell subpopulation that is highly enriched in proliferative and Ig secretory activity and binds to hyaluronate. J. Immunol. 145:3618-3627.

22. Lesley, J., N. Howes, A. Perschl, and R. Hyman. 1994. Hyaluronan binding function of CD44 is transiently activated on T cells during an in vivo immune response. J. Exp. Med. 180:383-387.

23. Stamenkovic, I., A. Aruffo, M. Amiot, and B. Seed. 1991. The hematopoietic and epithelial forms of CD44 are distinct polypeptides with different adhesion potentials for hyaluronate-bearing cells. EMBO (Eur. Mol. Biol. Organ.) J. 10:343-348.

24. Bourguignon, L.Y., V.B. Lokeshwar, J. He, X. Chen, and G.J. Bourguignon. 1992. A CD44-like endothelial cell transmembrane glycoprotein (GP116) interacts with extracellular matrix and ankyrin. Mol. Cell. Biol. 12:4464-4471.

25. Perschl, A., J. Lesley, N. English, R. Hyman, and I.S. Trowbridge. 1995. Transmembrane domain of CD44 is required for its detergent insolubility in fibroblasts. J. Cell Sci. 108:1033-1041.

26. Tsukita, S., K. Oishi, N. Sato, J. Sagara, A. Kawai, and S. Tsukita. 1994. ERM family members as molecular linkers between the cell surface glycoprotein CD44 and actin-based cytoskeletons. J. Cell Biol. 126:391-401.

27. Pure, E., R.L. Camp, D. Peritt, R.A. Panettieri, Jr., A.L. Lazaar, and S. Nayak. 1995. Defective phosphorylation and hyaluronate binding of CD44 with point mutations in the cytoplasmic domain. J. Exp. Med. 181:55-62.

28. Lesley, J., P.W. Kincade, and R. Hyman. 1993. Antibody-induced activation of the hyaluronan receptor function of CD44 requires multivalent binding by antibody. Eur. J. Immunol. 23:1902-1909.

29. Zheng, Z., S. Katoh, Q. He, K. Oritani, K. Miyake, J. Lesley, R. Hyman, A. Hamik, R.M.E. Parkhouse, A.G. Farr, and P.W. Kincade. 1995. Monoclonal antibodies to CD44 and their influence on hyaluronan recognition. J. Cell Biol. 130:485-495.

30. Katoh, S., Z. Zheng, K. Oritani, T. Shimozato, and P.W. Kincade. 1995. Glycosylation of CD44 negatively regulates its recognition of hyaluronan. $J$. Exp. Med. 182:419-429.

31. Lesley, J., N. English, A. Perschl, J. Gregoroff, and R. Hyman. 1995. Variant cell lines selected for alterations in the function of the hyaluronan receptor CD44 show differences in glycosylation. J. Exp. Med. 182:431-437.

32. Bennett, K.L., B. Modrell, B. Greenfield, A. Bartolazzi, I. Stamenkovic, R. Peach, D.G. Jackson, F. Spring, and A. Aruffo. 1995. Regulation of CD44 binding to hyaluronan by glycosylation of variably spliced exons. J. Cell Biol. 131:1623-1633.

33. Takahashi, K., I. Stamenkovic, M. Cutler, A. Dasgupta, and K.K. Tanabe. 1996. Keratan sulfate modification of CD44 modulates adhesion to hyaluronate. J. Biol. Chem. 271:9490-9496.

34. He, Q., J. Lesley, R. Hyman, K. Ishihara, and P.W. Kincade. 1992. Molecular isoforms of murine CD44 and evidence that the membrane proximal domain is not critical for hyaluronate recognition. J. Cell Biol. 119:1711-1719.

35. Johnson, A., and K. Dorshkind. 1986. Stromal cells in myeloid and lymphoid long-term bone marrow cultures can support multiple hemopoietic lineages and modulate their production of hemopoietic growth factors. Blood. 68: 1348-1354.

36. Palacios, R., and M. Steinmetz. 1985. IL3-dependent mouse clones that express B-220 surface antigen contain Ig genes in germ-line configuration, and generate B lymphocytes in vivo. Cell. 41:727-734.

37. Katoh, S., J.B. McCarthy, and P.W. Kincade. 1994. Characterization of soluble CD44 in the circulation of mice. Levels are affected by immune activity and tumor growth. J. Immunol. 153:3440-3449.

38. Wu, X., K. Miyake, K.L. Medina, P.W. Kincade, and J.M. Gimble. 1994. Recognition of murine integrin $\beta_{1}$ by a rat anti-stromal cell monoclonal antibody. Hybridoma. 13:409-416.

39. Do, K.-Y., S.-I. Do, and R.D. Cummings. 1997. Differential expression of LacdiNAc sequences (GalNAc $\beta 1-4$ GlcNAc-R) in glycoproteins synthesized by Chinese hamster ovary and human 293 cells. Glycobiology. 7:183-194.

40. Wilkins, P.P., R.P. McEver, and R.D. Cummings. 1996. Structures of the O-glycans on P-selectin glycoprotein ligand-1 from HL-60 cells. J. Biol. Chem. 271:18732-18742.

41. Varki, A. 1994. Metabolic radiolabeling of glycoconjugates. In Methods of Enzymology. W.J. Lennarz and G.W. Hart, editors. Academic Press, Inc., San Diego. 16-31.

42. Merkle, R.K., and R.D. Cummings. 1987. Lectin affinity chromatography of glycopeptides. In Methods of Enzymology. V. Ginsburg, editor. Academic Press, Inc., San Diego. 232-259.

43. Cummings, R.D. 1992. Synthesis of asparagine-linked oligosaccharides: pathways, genetics, and metabolic regulation. In Glycoconjugates. Composition, Structure and Function. H.J. Allen and E.C. Kisailus, editors. Marcel Dekker, Inc., New York. 333-360.

44. Schwarz, R.T., and R. Datema. 1982. Inhibition of the dolichol pathway of protein glycosylation. Methods Enzymol. 83:432-443.

45. Elbein, A.D. 1987. Inhibitors of the biosynthesis and processing of N-linked oligosaccharide chains. Annu. Rev. Biochem. 56:497-534.

46. Kojima, N., M. Saito, and S. Tsuji. 1994. Role of cell surface O-linked oligosaccharide in adhesion of HL60 cells to fibronectin: regulation of integrindependent cell adhesion by O-linked oligosaccharide elongation. Exp. Cell Res. 214:537-542. 
47. Sasaki, H., B. Bothrer, A. Dell, and M. Fukuda. 1987. Carbohydrate structure of erythropoietin expressed in Chinese hamster ovary cells by a human erythropoietin cDNA. J. Biol. Chem. 262:12059-12076.

48. Seguchi, T., R.K. Merkle, M. Ono, M. Kuwano, and R.D. Cummings. 1991. The dysfunctional LDL-receptor in a monensin-resistant mutant of Chinese hamster ovary cells lacks selected O-linked oligosaccharides. Arch. Biochem. Biophys. 284:245-256.

49. Rearick, J.I., A. Chapman, and S. Kornfeld. 1981. Glucose starvation alters lipid-linked oligosaccharide biosynthesis in Chinese hamster ovary cells. $J$. Biol. Chem. 256:6255-6261.

50. Fuhrmann, U., E. Bause, and H. Ploegh. 1985. Inhibitors of oligosaccharide processing. Biochem. Biophys. Acta. 825:95-110.

51. Lesley, J., and R. Hyman. 1992. CD44 can be activated to function as an hyaluronic acid receptor in normal murine T cells. Eur. J. Immunol. 22:27192723.

52. Shtivelman, E., and J.M. Bishop. 1991. Expression of CD44 is repressed in neuroblastoma cells. Mol. Cell. Biol. 11:5446-5453.

53. Turley, E.A., A.J. Belch, S. Poppema, and L.M. Pilarski. 1993. Expression and function of a receptor for hyaluronan-mediated motility on normal and malignant B lymphocytes. Blood. 81:446-453.

54. McCourt, P.A.G., B. Ek, N. Forsberg, and S. Gustafson. 1994. Intercellular adhesion molecule-1 is a cell surface receptor for hyaluronan. J. Biol. Chem. 269:30081-30084.

55. Yannariello-Brown, J., B. Zhou, and P.H. Weigel. 1997. Identification of a $175 \mathrm{kDa}$ protein as the ligand-binding subunit of the rat liver sinusoidal endothelial cell hyaluronan receptor. Glycobiology. 7:15-21.

56. Jalkanen, S., M. Jalkanen, R. Bargatze, M. Tammi, and E.C. Butcher. 1988. Biochemical properties of glycoproteins involved in lymphocyte recognition of high endothelial venules in man. J. Immunol. 141:1615-1623.

57. Brown, T.A., T. Bouchard, T. St. John, E. Wayner, and W.G. Carter. 1991. Human keratinocytes express a new CD44 core protein (CD44E) as a heparan-sulfate intrinsic membrane proteoglycan with additional exons. J. Cell Biol. 113:207-221.

58. Sutherland, D.R., K.M. Abdullah, P. Cyopick, and A. Mellors. 1992. Cleavage of the cell-surface $O$-sialoglycoproteins CD34, CD43, CD44, and CD45 by a novel glycoprotease from Pasteurella haemolytica. J. Immunol. 148: $1458-1464$.

59. Lokeshwar, V.B., and L.Y. Bourguignon. 1991. Post-translational protein modification and expression of ankyrin-binding site(s) in GP85 (Pgp-1/ CD44) and its biosynthetic precursors during T-lymphoma membrane biosynthesis. J. Biol. Chem. 266:17983-17989.

60. Datema, R., and R.T. Schwarz. 1978. Formation of 2-deoxyglucose-containing lipid-linked oligosaccharides. Interference with glycosylation of glycoproteins. Eur. J. Biochem. 90:505-516.

61. Jalkanen, S., and M. Jalkanen. 1992. Lymphocyte CD44 binds the COOH-terminal heparin-binding domain of fibronectin. J. Cell Biol. 116:817-825.
62. Faassen, A.E., J.A. Schrager, D.J. Klein, T.R. Oegema, J.R. Couchman, and J.B. McCarthy. 1992. A cell surface chondroitin sulfate proteoglycan, immunologically related to CD44, is involved in type I collagen-mediated melanoma cell motility and invasion. J. Cell Biol. 116:521-531.

63. Brissett, N.C., and S.J. Perkins. 1996. The protein fold of the hyaluronate-binding proteoglycan tandem repeat domain of link protein, aggrecan and CD44 is similar to that of the C-type lectin superfamily. FEBS (Fed. Eur. Biochem. Soc.) Lett. 388:211-216.

64. Kohda, D. C.J. Morton, A.A. Parkar, H. Hatanaka, F.M. Inagaki, I.D. Campbell, and A.J. Day. 1996. Solution structure of the link module: a hyaluronan-binding domain involved in extracellular matrix stability and cell migration. Cell. 86:767-775.

65. Bartolazzi, A., A. Nocks, A. Aruffo, F. Spring, and I. Stamenkovic. 1996. Glycosylation of CD44 is implicated in CD44-mediated cell adhesion to hyaluronan. J. Cell Biol. 132:1199-1208.

66. Toyama-Sorimachi, N., H. Sorimachi, Y. Tobita, F. Kitamura, H. Yagita, K. Suzuki, and M. Miyasaka. 1995. A novel ligand for CD44 is serglycin, a hematopoietic cell lineage-specific proteoglycan. Possible involvement in lymphoid cell adherence and activation. J. Biol. Chem. 270:7437-7444.

67. Weber, G.F., S. Ashkar, M.J. Glimcher, and H. Cantor. 1996. Receptorligand interaction between CD44 and osteopontin (Eta-1). Science (Wash. DC) 271:509-512.

68. Naujokas, M.F., M. Morin, M.S. Anderson, M. Peterson, and J. Miller. 1993. The chondroitin sulfate form of invariant chain can enhance stimulation of $\mathrm{T}$ cell responses through interaction with CD44. Cell. 74:257-268.

69. Isacke, C.M. 1994. The role of the cytoplasmic domain in regulating CD44 function. J. Cell Sci. 107:2353-2359.

70. Guo, Y., J. Ma, J. Wang, X. Che, J. Narula, M. Bigby, M. Wu, and M.-S. Sy. 1994. Inhibition of human melanoma growth and metastasis in vivo by antiCD44 monoclonal antibody. Cancer Res. 54:1561-1565.

71. Stark, N.J., and E.C. Heath. 1979. Glucose-dependent glycosylation of secretory glycoprotein in mouse myeloma cells. Arch. Biochem. Biophys. 192: 599-609.

72. Mueller-Klieser, W., and S. Walenta. 1993. Geographical mapping of metabolites in biological tissue with quantitative bioluminescence and single photon imaging. Histochem. J. 25:407-420.

73. Tamulevicius, P., and C. Streffer. 1995. Metabolic imaging in tumours by means of bioluminescence. Br. J. Cancer. 72:1102-1112.

74. Romarís, M., A. Bassols, and G. David. 1995. Effect of transforming growth factor- $\beta 1$ and basic fibroblast growth factor on the expression of cell surface proteoglycans in human lung fibroblasts. Enhanced glycanation and fibronectin-binding of CD44 proteoglycan, and down-regulation of glypican. Biochem. J. 310:73-81.

75. Levesque, M.C., and B.F. Haynes. 1996. In vitro culture of human peripheral blood monocytes induces hyaluronan binding and up-regulates monocyte variant CD44 isoform expression. J. Immunol. 156:1557-1565. 